\title{
Macroporous materials by self-assembly of linear oligo(phenylsilsesquioxanes)
}

\author{
A. Kowalewska*, M. Nowacka, T. Makowski \\ Centre of Molecular and Macromolecular Studies, Polish Academy of Science, Sienkiewicza 112, 90-363 Lodz, Poland
}

Received 27 January 2015; accepted in revised form 26 June 2015

\begin{abstract}
Materials with macroporous architecture were prepared in a template-free system using linear oligo(phenylsilsesquioxanes) (Ph-LPSQ), obtained in a two-step, one-pot, acid/base sol-gel method. The spontaneous self-assembly of silsesquioxane chains is governed by $\pi$ - $\pi$ interactions between side substituents and facilitated by the backbone rigidity of the polymer. The porous structure of the material can be changed on adjusting the processing conditions (concentration of Ph-LPSQ solution, the ratio solvent/nonsolvent and rate of stirring during precipitation). Ph-LPSQ oligomers can be also used for modification of silica particles and preparation of interesting macro-mesoporous materials of narrow pore size. Morphology and properties of the polymer and self-assembled particles were characterized by nuclear magnetic resonance (NMR) and Fourier transform infrared (FTIR) spectroscopies, wide angle X-ray scattering (WAXS), scanning electron microscopy SEM, mercury intrusion porosimetry, fluorescence spectroscopy and dynamic light scattering.
\end{abstract}

Keywords: molecular engineering, ladder phenylsilsesquioxanes, sol-gel, self-assembly, micropspheres

\section{Introduction}

Nano- and microstructured polymeric materials of well-defined composition, morphology and function are of general scientific importance and technological interest. For example, solid or hollow polymeric spheres can be applied for controlled storage and release, in catalysis, as photonic crystals and templates to macroporous materials [1]. Several types of mesoporous silica [2] have also found many technological applications due to their morphological characteristics [3-6]. Monolithic silica or silsesquioxane gels with hierarchical well-defined macropores and shape-controlled mesopores exhibit low or no shrinkage during drying. They attract large interest in separation techniques, in catalysis, micro- and optoelectronics (e.g. chromatographic stationary phases for HPLC and UPLC flexible aerogels, superhydrophobic materials, insulating coatings, biomedical entrapment materials) [7].
Macroporous structure of silica monoliths can be generated in the course of hydrolytic polycondensation of alkoxysilanes, due to coexisting phase separation and gelation phenomena [8]. Macroporous materials were also obtained by aggregation and gelation of PEG-stabilized silica particles [9] or in silicone oil dispersions [10]. Macroporous poly (methylsilsesquioxanes) (MSQ) were prepared by micellar nanoscale templating combined with polymerization-induced phase microseparation $[11,12]$ in a two-step process of all-acidic hydrolytic polycondensation [13] or using an acid/base two step processing method [7, 14]. Macro-mesoporous silica materials can also be prepared by dual templating using supramolecular systems [15-17]. However, to our best knowledge there are no reports on macroporous structures based on poly(phenylsilsesquioxanes). Such materials would be of special interest owing to their low polarity and possible

\footnotetext{
${ }^{*}$ Corresponding author, e-mail: anko@cbmm.lodz.pl

(C) BME-PT
} 
interactions with biological systems. However, the literature reports concern poly(phenylsilsesquioxane) microparticles obtained in a modified Stöber route $[18,19]$ emulsion polymerization [20], a template-free two-step acid-base catalyzed sol-gel process $[21,22]$ and base catalyzed oil-in-water emulsion polycondensation [19]. Phenylsilsesquioxane particles of 'core-shell' structure show both thermoplastic and thermosetting properties [23, 24]. Ladder-like polysilsesquioxanes structurally differ from polyhedral oligomeric silsesquioxanes (POSS) and random silsesquioxane networks (Figure 2). They gain a growing interest due to their unique physiochemical properties (good solubility, film-forming properties, morphological-stability, excellent thermochemical resistance) [25-27]. Poly(phenylsilsesquioxanes) show high thermal stability (degradation onset temperatures about $793 \mathrm{~K}$ in air) and good mechanical properties [28]. For most of the poly(phenylsilsesquioxanes), the characteristic ten-

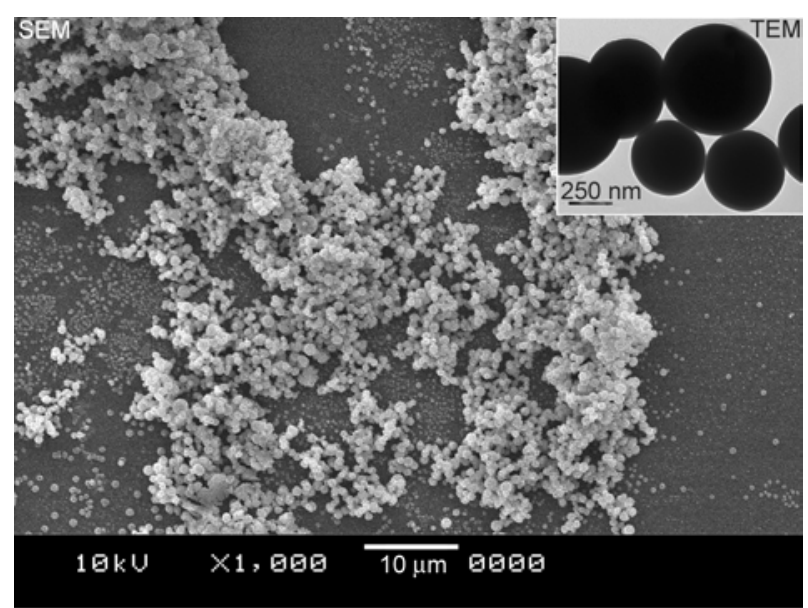

Figure 1. Spherical particles obtained by self-assembly of oligomeric Ph-LPSQ (polymer concentration in $\mathrm{CH}_{2} \mathrm{Cl}_{2}=50 \mathrm{mg} / \mathrm{cm}^{3}$, hexane $/ \mathrm{CH}_{2} \mathrm{Cl}_{2} \mathrm{v} / \mathrm{v}=1000$, the insert contains a TEM micrograph of the formed microspheres) sile strength value is in the range of $20-40 \mathrm{MPa}$ and the elongation 3-20\% [29]. They are less hard and brittle than poly(methylsilsesquioxanes) [30]. It was found that rheological properties of organic polymer blends (strain hardening/softening under dynamic shear and uniaxial elongation) can change on addition of Ph-LPSQ [31].

The application of poly(phenylsilsesquioxane)based materials encompasses membranes [32], interlayer dielectrics [33], protective coating films in electronics [34] optical devices [35] and thermostable superhydrophobic coatings [36]. Poly(phenylsilsesquioxane)-derived materials were also used as pre-ceramic precursors for hierarchically porous silicon oxycarbide-derived carbons for supercapacitor electrodes [37] and low dielectric constant porous matrix [38]. Composite materials based on $\mathrm{Ph}-$ LPSQ include well-defined inorganic-organic hybrid block copolymers of enhanced thermal properties [39], materials of improved the elongation at break, flexural strength and flame-retardancy [40], fibers [41]. Other applications include their use in carbon fiber/ceramic matrix composites [42], and also drug delivery [43].

We have found that linear oligosilsesquioxanes bearing side phenyl groups (Ph-LPSQ) can self-assemble and form spherical nano- and microstructures in template-free systems (Figure 1). Such microparticles made of Ph-LPSQ oligomers can be used for preparation of mesoporous materials and also for modification of silica microspheres. Morphology and properties of the self-assembled objects were studied using SEM microscopy, mercury intrusion porosimetry, fluorometry and dynamic light scattering.

Formation of macropores in the reported system, conversely to MSQ monoliths, is not governed by polymerization-induced phase separation. Instead, a
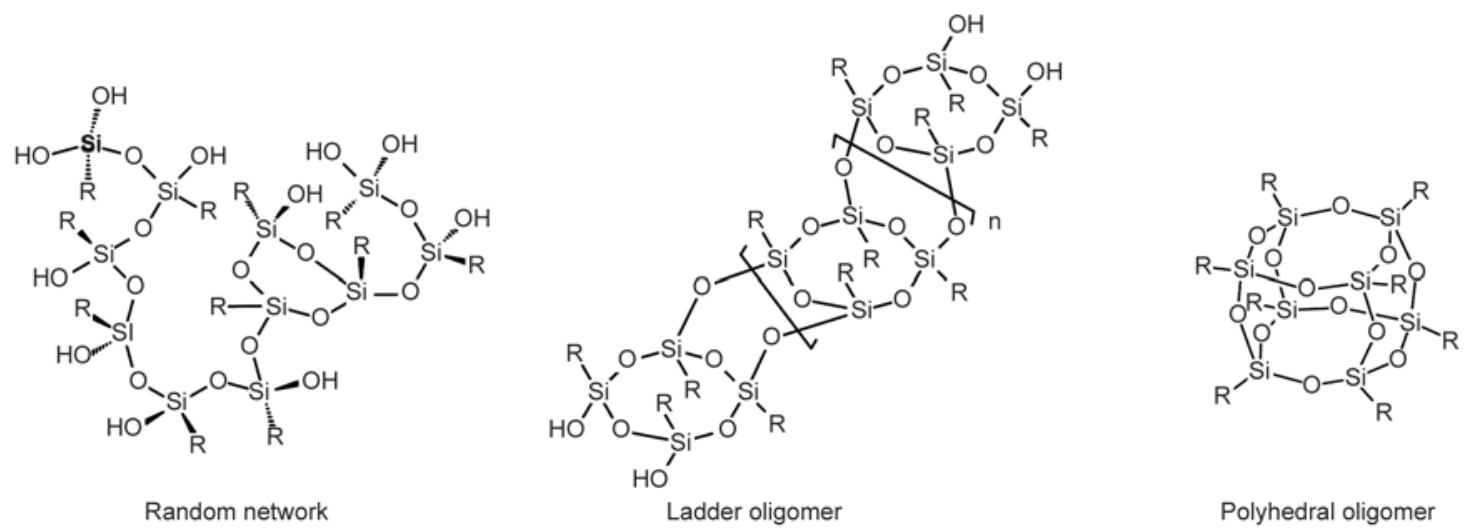

Figure 2. Various structural types of silsesquioxane polymers and oligomers 
spontaneous self-assembly of oligomeric silsesquioxanes takes place, owing to $\pi-\pi$ interactions between side substituents and the backbone rigidity. It is known that $\pi-\pi$ aromatic interactions can play an important role in the organization of Ph-LPSQ systems (including their crystallization [44, 45] and co-crystalization [46]). $\pi-\pi$ templating with ladderlike Ph-LPSQ was also used for controlled, onedimensional (linear) chain growth in the sol-gel polymerization of phenyltrimethoxysilane [47].

It is expected that such structured particles could possibly find an application as precursors to ceramic silicon-oxycarbide microspheres with high $\mathrm{C} / \mathrm{Si}$ ratio, macroporous templates and chromatographic stationary phases.

\section{Experimental section}

\subsection{Materials and methods}

\subsubsection{Reagents}

Triethoxyphenylsilane (98\%, Aldrich, Poznan, Poland), tetraethylorthosilicate (TEOS, 98\%, Aldrich, Poznan, Poland), hydrochloric acid (aqueous solution 35-38 wt\%, POCh, Gliwice, Poland) and ammonium hydroxide aqueous solution $(25 \mathrm{wt} \%$, POCh, Gliwice, Poland) were used as received. Model linear Ph-LPSQ of regular structure was prepared as earlier reported [48]. Solvents were purified according to literature procedures [49].

\subsubsection{Instrumentation}

Solid-state ${ }^{13} \mathrm{C}$ and ${ }^{29} \mathrm{Si}$ CPMAS NMR spectra were recorded on an AV-400 Bruker spectrometer (Billerica, MA, USA) at $59.627 \mathrm{MHz}$. The peak positions were referenced to the signal of $\mathrm{Q}_{8} \mathrm{M}_{8}$ (trimethylsilyl ester of cubic octameric silicate) as standard. Wide-angle X-ray scattering (WAXS) measurements were performed using source of $\mathrm{CuK} \alpha$ radiation (Philips), operating at $30 \mathrm{kV}$ and $50 \mathrm{~mA} \mathrm{X}$-ray beam. The diffraction patterns were recorded in the $2 \theta$ range from 3 to $45^{\circ}$ and are presented as functions of the scattering vector $d$, where $d=1 / s ; s=$ $2 \sin (\pi 2 \theta / 360) / 0.154$, where $2 \theta$ is the scattering angle. Typical time of acquisition was $30 \mathrm{sec}$. The samples were prepared as powder and were irradiated at the incident angle $\left(\alpha_{\mathrm{i}}\right)$ of $0.05^{\circ}$.

Mass spectrometric measurements (MALDI-TOF) were recorded on a Voyager-Elite (PerSeptive Biosystems, Framingham, MS, USA) time-of-flight instrument equipped with a pulsed $\mathrm{N}_{2}$ laser $(337 \mathrm{~nm}$, 4-ns pulse width) and time-delayed extraction ion source. An accelerating voltage of $20 \mathrm{kV}$ was applied. Mass spectra were recorded in the linear positive ion mode using 1,8-dihydroxy-9-anthracenone (ditranol, DT) as the matrix and $\mathrm{LiCl}, \mathrm{KO}(\mathrm{O}) \mathrm{CCF}_{3}$ or $\mathrm{AgO}(\mathrm{O}) \mathrm{CCF}_{3}$ as cationization agents. For size exclusion chromatography (SEC) an Agilent 1100 series chromatograph (Agilent, Santa Clara, CA, USA) composed of degasser, pump, and autosampler was used. Two PL Gel $5 \mu \mathrm{m}$ MIXED-C columns $(7.8 \times 300 \mathrm{~mm})$ were employed in a series (temperature $300 \mathrm{~K}$ ). RI (OPTILAB T-rex, Wyatt, Santa Barbara, CA, USA) and MALLS $(\lambda=682 \mathrm{~nm}$, DAWN HEOS, II, Wyatt, Santa Barbara, CA, USA) were used as detectors. The mobile phase was dichloromethane at a flow rate of $0.8 \mathrm{~cm}^{3} / \mathrm{min}$. Samples (concentration of polymers: $7 \mathrm{mg} / \mathrm{cm}^{3}$ ) were dissolved in $\mathrm{CH}_{2} \mathrm{Cl}_{2}$ and passed through $0.2 \mu \mathrm{m}$ pore size SRP membrane filters. Injection volumes of the sample solutions were $100 \mu \mathrm{L}$. Molecular masses were derived from a calibration curve based on polystyrene standards and Astra 4.90.07 software was used to treat the data.

Phase transitions of polymers were studied by differential scanning calorimetry (DSC) technique [DuPont 2000 thermal analysis system (TA Instruments, New Castle, DE, USA)]. Thermograms were taken for samples (sealed in aluminium pans) quenched from the amorphous phase (room temperature) and then heated $(10 \mathrm{~K} / \mathrm{min})$ from 273 to $523 \mathrm{~K}$. The sample was kept at $523 \mathrm{~K}$ for 3 min to erase any thermal history. Subsequently, it was cooled to $273 \mathrm{~K}$ and heated again to $523 \mathrm{~K}$. Thermogravimetric analysis (TGA) was performed using a Hi-Res TGA 2950 Thermogravimetric Analyzer (TA Instruments, New Castle, DE, USA). The analysis was performed under nitrogen from room temperature to $1173 \mathrm{~K}$. The heating rate was $10 \mathrm{~K} / \mathrm{min}$.

Diameters of microspheres and micelles formed during the precipitation in nonsolvents were measured at $298 \mathrm{~K}$ using a Zetasizer Nano ZEN3600, (Malvern, UK) equipped with a quartz cell. Fluorescence spectra of Ph-LPSQ (in solution and as a suspension) were recorded at room temperature by means of a Horiba Jobin Yvon, Fluorolog-3 spectrofluorometer (Kyoto, Japan) using indicated excitation wavelengths.

Diameters and shape of the precipitated particles were determined by analysis of scanning electron microscopy (SEM) microphotographs. Microstructured samples were dispersed in hexanes and placed on a silicon wafer. They were left for drying at room 
temperature. SEM images were taken with a JEOL JSH 5500 LV scanning electron microscope (Tokyo, Japan) in high-vacuum mode at the accelerated voltage of $10 \mathrm{kV}$. Samples were sputter coated with a fine gold layer, about $20 \mathrm{~nm}$ thick using ion coating JEOL JFC 1200 apparatus (Tokyo, Japan). For Transmission Electron Microscopy (TEM) analysis [micrographs were taken with Tesla BS 512 with YAG camera (TESLA, Czechoslovakia)] a small drop of not stained dispersion of micelles in a non-solvent was deposited on a copper grid.

Macropore intrusion volumes and macropore size distributions were measured by mercury intrusion porosimetry on an AutoPore 9220 (Micromeritics Instruments, Norcross, GA, USA) over a pressure range of $4136.8 \mathrm{~Pa}-345 \mathrm{MPa}$ and analyzed using the Washburn equation. Before the analysis, all samples were dried [Memmert 200 dryer (Memmert $\mathrm{GmbH}$, Germany)] to constant weight at $308 \mathrm{~K}$ for at least $24 \mathrm{~h}$ to remove air, and directly measured thereafter.

Nitrogen sorption data were collected with a Micromeritics ASAP 2020 instrument (Micromeritics Instruments, Norcross, GA, USA). Before each nitrogen adsorption-desorption measurement, the samples were degassed at ambient temperature overnight and directly measured thereafter. The isotherms were measured at liquid nitrogen temperature. Specific surface area and pore size distributions were determined using, respectively, the BET (BrunauerEmmett-Teller) and the BJH (Barrett-Joyner-Halenda) model.

\subsection{Synthesis}

\subsubsection{Preparation of Ph-LPSQ by} polycondensation of oligomeric silanols pre-formed by acidic hydrolysis of PhSi $(\text { OEt })_{3}$

Hydrochloric acid was added drop-wise to a stirred mixture of $\mathrm{PhSi}(\mathrm{OEt})_{3}$ and deionised $\mathrm{H}_{2} \mathrm{O}$. The mixture was left at a given temperature with stirring for a given time (Table 1). The reaction mixture became transparent, indicating complete hydrolysis of alkoxysilyl groups. $\mathrm{NH}_{4} \mathrm{OHaq}$ was then added dropwise with stirring to the obtained sol. The reaction mixture was allowed to solidify at a given temperature for a given time. The polymeric product was dissolved in a small amount of $\mathrm{CH}_{2} \mathrm{Cl}_{2}$ and precipitated into large volumes of $\mathrm{MeOH}$. Precipitation was repeated trice and polymer fractions differing by their molar mass and molar mass distribution were separated.

${ }^{13} \mathrm{C} \mathrm{NMR} ; \delta[\mathrm{ppm}]: 134.8,131.0,130.3,127.8(\mathrm{Ph})$

${ }^{29} \mathrm{Si} \mathrm{NMR} ; \delta[\mathrm{ppm}]:-62\left[\mathrm{PhSi}(\mathrm{OH})_{2} \mathrm{O}_{1 / 2}\right]\left(\mathrm{T}^{1}\right),-70$

$\left[\mathrm{PhSi}(\mathrm{OH}) \mathrm{O}_{2 / 2}\right]\left(\mathrm{T}^{2}\right),-79\left(\mathrm{PhSiO}_{3 / 2}\right)\left(\mathrm{T}^{3}\right)$.

\subsubsection{Formation of micelles and structured materials in nonsolvents}

Ph-LPSQ $\left(M_{\mathrm{w}}(\right.$ MALLS $\left.)=2500, M_{\mathrm{w}} / M_{\mathrm{n}}=1.3\right)$ was dissolved in dry dichlorometane at a given concentration, and added drop-wise to a stirred nonsolvent (hexanes or EtOH). The microstructured precipitate was filtered and washed with a copious volume of the nonsolvent, then dried to constant weight at room temperature in a vacuum desiccator.

Samples for DLS experiments were prepared using a solution of Ph-LPSQ in $\mathrm{CH}_{2} \mathrm{Cl}_{2}$ filtered through $0.2 \mu \mathrm{m}$ PTFE membrane. A given volume was added with stirring (1000 rpm) to the nonsolvent and immediately transferred to a quartz cuvette and placed in the sample compartment of Zetasizer Nano ZEN3600.

\subsubsection{Preparation of $\mathrm{Ph}-\mathrm{LPSQ}-\mathrm{SiO}_{2}$ composites by condensation of oligomeric Ph-LPSQ onto silica microspheres}

Silica microspheres were obtained following the procedure: ethanol $\left(54 \mathrm{~cm}^{3}\right), \mathrm{NH}_{4} \mathrm{OH}\left(2.6 \mathrm{~cm}^{3}\right.$ $26 \mathrm{wt} \%)$ and $\mathrm{H}_{2} \mathrm{O}\left(1.0 \mathrm{~cm}^{3}\right)$ were mixed and heated at $323 \mathrm{~K}$ for 30 minutes. Tetraethoxysilane $(1.9 \mathrm{~g}$, $0.009 \mathrm{~mol}$ ) was added slowly dropwise to the solution stirred at $1000 \mathrm{rpm}$ and the resulting mixture was heated at $323 \mathrm{~K}$ for $24 \mathrm{~h}$. The mixture becomes turbid after about 5 minutes due to the formation of $\mathrm{SiO}_{2}$ particles $(\varphi=0.2-0.5 \mu \mathrm{m}$ by SEM).

Ph-LPSQ $\left(0.19 \mathrm{~g} ; M_{\mathrm{w}}(\right.$ MALLS $)=2500, M_{\mathrm{w}} / M_{\mathrm{n}}=$ 1.3) was dissolved in $4 \mathrm{~cm}^{3}$ of $\mathrm{CH}_{2} \mathrm{Cl}_{2}$ and added drop-wise to the suspension over 10 minutes. The mixture was heated at $323 \mathrm{~K}$ for 24 hours and then admixed with $15 \mathrm{~cm}^{3}$ of dry toluene and refluxed at $383 \mathrm{~K}$ for 8 hours using a Dean-Stark apparatus. The volume of the reaction mixture was reduced by $70 \%$ and the residue was precipitated by addition to hexanes $\left(100 \mathrm{~cm}^{3}\right)$. It was dried to a constant weight $\left(0.7 \mathrm{~g}\right.$ ), then dissolved in $\mathrm{CH}_{2} \mathrm{Cl}_{2}\left(14 \mathrm{~cm}^{3}\right)$ (a turbid solution was formed) and precipitated again in hexanes $\left(1400 \mathrm{~cm}^{3}\right)$. 


\section{Results and discussion}

\subsection{Synthesis, structure and physiochemical properties of Ph-LPSQ}

Polymeric Ph-LPSQs were prepared by one-pot, twostep, acid-base catalyzed hydrolytic polycondensation of phenyltriethoxysilane carried out in bulk. The method does not yield highly cross-linked resins but soluble polymeric materials, which can be explained on the basis of two different mechanisms that can occur during a sol-gel process, depending on $\mathrm{pH}$ of the reaction mixture [50]. Rapid protonation of ethoxide groups is the first step in acid catalysed hydrolysis of $\mathrm{PhSi}(\mathrm{OEt})_{3}$, which makes it more susceptible to hydrolysis. Under such conditions the hydrolysis of alkoxy groups is nearly complete before the beginning of the condensation of silanols (Figure 3). Primary silanols become preferentially protonated and thus more prone to nucleophilic attack. Unprotonated silanols present in the reaction mixture operate as basic species and react with their protonated counterparts yielding siloxane bonds. Basicity of silanol groups decreases with increasing number of siloxane bonds at the respective silicon atom. Therefore, under acidic conditions monomeric species tend to react with oligomers of the least degree of condensation. Consequently, linear or weakly branched structures are mostly formed. Secondary silanols are activatied for condensation in alkaline conditions, by deprotonation of $\mathrm{SiOH}$ groups and formation of silanolate anions. These strong nucleophiles tend to deprotonate most acidic silanols in the oligomeric chain (the side ones). The preferential activation of side silanols in linear oligomers in the twostep, acid-base catalyzed sol-gel process, as well as steric and electronic factors caused by side phenyl groups, result in formation of Ph-LPSQ of ladderlike structure. Obviously, the silsesquioxane backbone of the obtained products is statistically more branched than that prepared by stepwise coupling polycondensation method [48]. The influence of synthetic conditions $\left([\mathrm{SiOEt}]_{0} /\left[\mathrm{H}_{2} \mathrm{O}\right]_{0},\left[\mathrm{NH}_{4} \mathrm{OH}\right]_{0} /\right.$
$[\mathrm{SiOEt}]_{0}$, time and temperature of the process at constant $\left.[\mathrm{HCl}]_{0} /[\mathrm{SiOEt}]_{0}=2.2 \cdot 10^{-4}\right)$ on the structure of product was studied (Table 1). Polymers of $M_{\mathrm{w}}$ (MALLS) 2500-23000 u. were obtained. Their purification by precipitation into $\mathrm{MeOH}$ allowed for fractionation of oligomers by their molecular mass.

MALDI TOF spectroscopy was applied to elucidate the structure of Ph-LPSQ obtained with the two-step method (Figures 4 and 5). Tentative assignment of peaks in MALDI-TOF spectra (Figure 4) suggests that the oligomers can indeed be linear. Species containing completely condensed $\mathrm{PhSiO}_{2 / 2}$ units and additionally incompletely condensed groups $\left[\mathrm{PhSiO}_{2 / 2}(\mathrm{OH})\right.$ and $\left.\mathrm{PhSiO}_{1 / 2}(\mathrm{OH})_{2}\right]$ dominate in the mixture. Oligosilsesquioxanes of low molecular mass $(\mathrm{m} / \mathrm{z}<1000 \mathrm{u})$ can fold and form cage-like architectures $[51,52]$. However, only a very small number of the obtained Ph-LPSQ species can be assigned to cyclic structures (along their linear-branched counterparts) which can be attributed to the synthetic method (polycondensation in bulk). Only those, that can correspond to incompletely closed silsesqioxane cages $\left[\left(\mathrm{T}^{3}\right)_{8}\left(\mathrm{~T}^{2}\right)_{2}\right.$ and $\left(\mathrm{T}^{3}\right)_{10}\left(\mathrm{~T}^{2}\right)_{2} ; m / z 1316.9 \mathrm{u}$ and $1575.0 \mathrm{u}$ ] are more abundant. Microstructural analysis of oligo(phenylsilsesquioxanes) obtained under various reaction conditions (Figure 5) proved the propensity of the system to form linear oligomers at low temperatures, with high amount of $\mathrm{H}_{2} \mathrm{O}$ and at increased time of condensation under acidic conditions. Branched species are more easily formed at higher temperatures.

Regularity of the structure of Ph-LPSQ chains cannot be proved by a MALDI spectrum alone. Wide angle X-ray diffraction (WAXS) data collected for the prepared materials (Figure 6) were compared with the diffraction pattern of cis-isotactic Ph-LPSQ obtained following the reported stepwise coupling polycondensation procedure [48]. WAXS diffractograms of both amorphous polymers are almost identical and suggest the presence of ladder segments $\left(d_{1}\right)$. However, there are discernible differ-

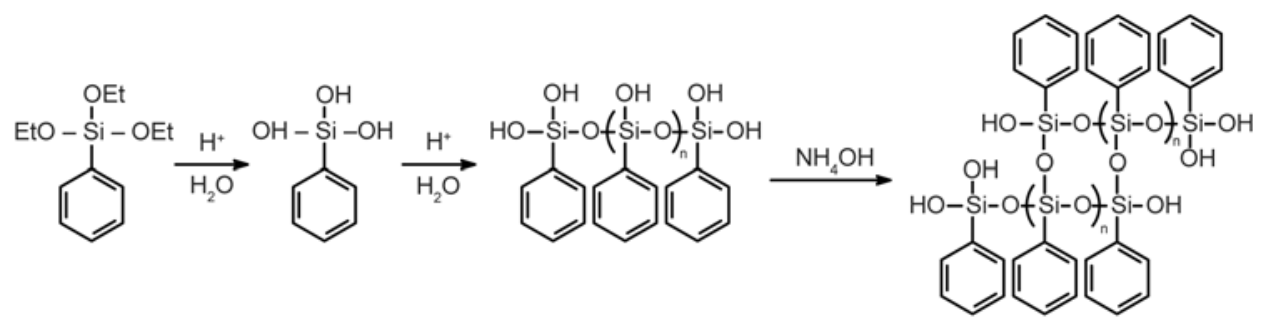

Figure 3. Preparation of Ph-LPSQ by two-step, acid-base catalyzed hydrolytic polycondensation of $\mathrm{PhSi}(\mathrm{OEt})_{3}$ 
$1 \quad\left(\mathrm{~T}^{3}\right)_{12}\left(\mathrm{~T}^{2}\right)_{3} \mathrm{Li}^{+}$

$2 \quad\left(\mathrm{~T}^{3}\right)_{11}\left(\mathrm{~T}^{2}\right)_{3}\left(\mathrm{~T}^{1}\right)_{1} \mathrm{Li}$

$3\left(T^{3}\right)_{10}\left(T^{2}\right)_{3}\left(T^{1}\right)_{2}^{+}$

$4 \quad\left(\mathrm{~T}^{3}\right)_{9}\left(\mathrm{~T}^{2}\right)_{3}\left(\mathrm{~T}^{1}\right)_{3}{ }^{+}$

$\left(\mathrm{T}^{3}\right)_{8}\left(\mathrm{~T}^{2}\right)_{3}\left(\mathrm{~T}^{1}\right)_{4}{ }^{+}$

$\left(\mathrm{T}^{3}\right)_{7}\left(\mathrm{~T}^{2}\right)_{5}\left(\mathrm{~T}^{1}\right)_{3} \mathrm{Li}^{+}$
$7 \quad\left(\mathrm{~T}^{3}\right)_{14}\left(\mathrm{~T}^{2}\right)_{4} \mathrm{Li}^{+}$

$8 \quad\left(\mathrm{~T}^{3}\right)_{12}\left(\mathrm{~T}^{2}\right)_{4} \mathrm{Li}^{+}$

$\left(\mathrm{T}^{3}\right)_{10}\left(\mathrm{~T}^{2}\right)_{6} \mathrm{Li}^{+}$

$0 \quad\left(\mathrm{~T}^{3}\right)_{10}\left(\mathrm{~T}^{2}\right)_{6} \mathrm{Li}_{2}{ }^{+}$

$11 \quad\left(\mathrm{~T}^{3}\right)_{8}\left(\mathrm{~T}^{2}\right)_{8} \mathrm{Li}_{2}{ }^{+}$

$12\left(\mathrm{~T}^{3}\right)_{6}\left(\mathrm{~T}^{2}\right)_{10} \mathrm{Li}_{2}{ }^{+}$
$131+\left(\mathrm{T}^{3}\right)_{2}$

$142+\left(\mathrm{T}^{3}\right)_{2}$

$153+\left(T^{3}\right)_{2}$

$16 \quad 4+\left(T^{3}\right)_{2}$

$175+\left(\mathrm{T}^{3}\right)_{2}$

$186+\left(T^{3}\right)_{2}$
$197+\left(\mathrm{T}^{3}\right)_{2}$

$208+\left(T^{3}\right)_{2}$

$219+\left(\mathrm{T}^{3}\right)_{2}$

$2210+\left(\mathrm{T}^{3}\right)_{2}$

$2311+\left(\mathrm{T}^{3}\right)_{2}$

$2412+\left(\mathrm{T}^{3}\right)_{2}$

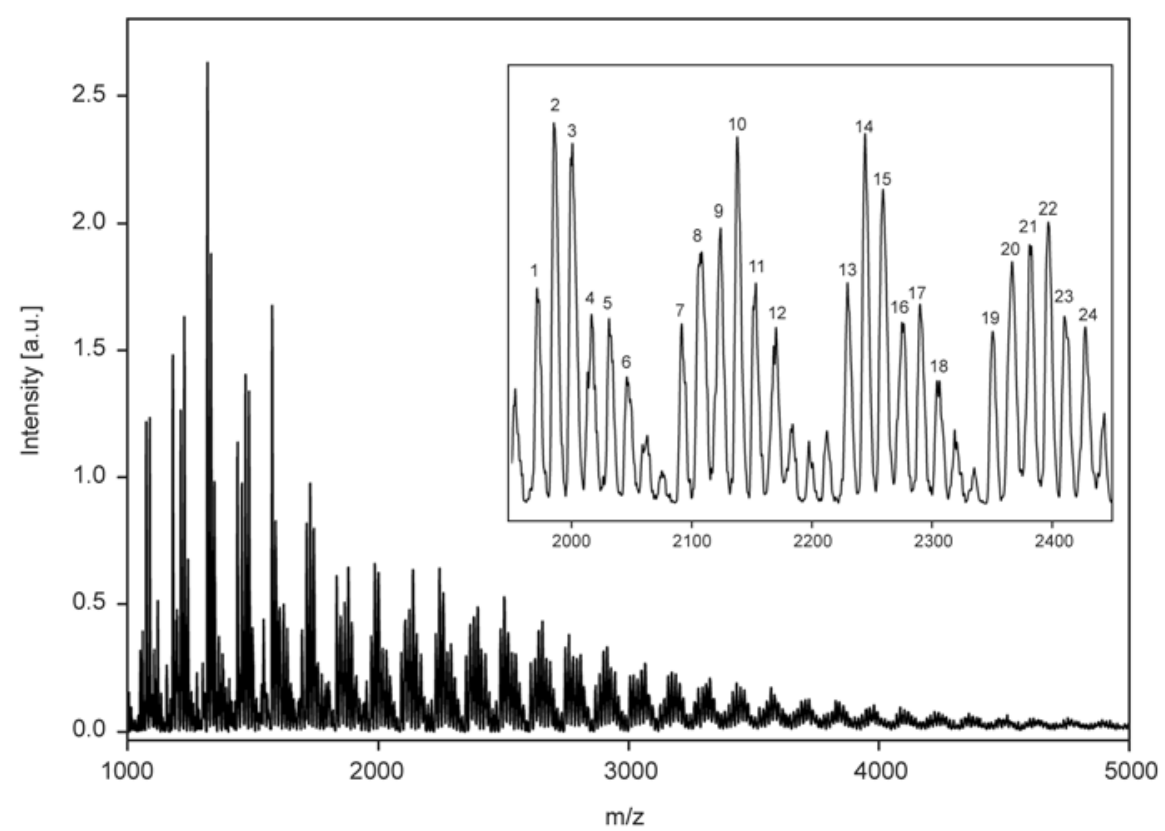

Figure 4. MALDI TOF spectrum $\left(\mathrm{DT}, \mathrm{Li}^{+}\right)$of Ph-LPSQ [sample $1 \mathrm{a}, M_{\mathrm{w}}(\mathrm{MALLS})=2500, M_{\mathrm{w}} / M_{\mathrm{n}}=1.3($ Table 1$)$ ]

Table 1. Reaction conditions applied for the synthesis of Ph-LPSQ $\left([\mathrm{HCl}]_{0} /[\mathrm{SiOEt}]_{0}=2.2 \cdot 10^{-4},\left[\mathrm{NH}_{4} \mathrm{OH}\right]_{0} /[\mathrm{SiOEt}]_{0}=\right.$ $1.7 \cdot 10^{-3}$, temperature of the post-condensation treatment $T_{3}=333 \mathrm{~K}$, time of the post-condensation treatment $\left.t_{3}=8 \mathrm{~h}\right)$

\begin{tabular}{|c|c|c|c|c|c|c|c|c|c|c|c|c|}
\hline No. & $\frac{[\mathrm{SiOEt}]_{0}}{\left[\mathrm{H}_{2} \mathrm{O}\right]_{0}}$ & $\begin{array}{c}\mathbf{T}_{1} \\
{[\mathbf{K}]}\end{array}$ & $\begin{array}{c}t_{1} \\
{[h]}\end{array}$ & $\begin{array}{c}\mathbf{T}_{\mathbf{2}} \\
{[\mathbf{K}]}\end{array}$ & $\begin{array}{c}\mathbf{t}_{2 \mathrm{a}} \\
{[\mathrm{min}]}\end{array}$ & $\begin{array}{l}\mathbf{t}_{2 b} \\
{[\mathrm{~h}]}\end{array}$ & fraction & $\begin{array}{c}\mathbf{Y} \\
{[\%]}\end{array}$ & $\mathbf{M}_{\mathbf{n}} \mathbf{R I}$ & PDI RI & $\begin{array}{c}\mathbf{M}_{\mathbf{w}} \\
\text { MALLS }\end{array}$ & $\begin{array}{c}\text { PDI } \\
\text { MALLS }\end{array}$ \\
\hline \multirow{4}{*}{$1^{*}$} & & & & & & & $1 \mathrm{a}$ & 58 & 1000 & 1.6 & 2500 & 1.3 \\
\hline & & & & & & & $1 \mathrm{~b}$ & 3 & 1300 & 1.4 & 3200 & 1.2 \\
\hline & & & & & & & $1 \mathrm{c}$ & 6 & 2000 & 1.4 & 4500 & 1.2 \\
\hline & & & & & & & $1 \mathrm{~d}$ & 31 & 2100 & 1.4 & 5000 & 1.2 \\
\hline 2 & 0.833 & 294 & 3 & 338 & 1 & 6 & - & 61 & 3400 & 2.2 & 13000 & 2.1 \\
\hline 3 & 0.833 & 294 & 18.5 & 338 & 1 & 6 & - & 61 & 3400 & 2.1 & 12000 & 1.9 \\
\hline 4 & 0.833 & 294 & 27 & 338 & 1 & 6 & - & 48 & 3700 & 1.9 & 11400 & 1.7 \\
\hline 5 & 0.833 & 294 & 42.5 & 338 & 1 & 6 & - & 52 & 2900 & 1.9 & 8300 & 1.8 \\
\hline $6^{*}$ & 0.335 & 303 & 48 & 303 & 1 & 24 & - & 58 & 2800 & 2.1 & 11000 & 1.8 \\
\hline 7 & 0.334 & 303 & 48 & 303 & 1 & 24 & - & 61 & 2800 & 2.1 & 11000 & 1.8 \\
\hline 8 & 0.333 & 303 & 48 & 303 & 1 & 24 & - & 58 & 2900 & 2.1 & 11000 & 1.6 \\
\hline 9 & 0.329 & 303 & 48 & 303 & 1 & 24 & - & 51 & 2900 & 2.0 & 10400 & 1.6 \\
\hline 10 & 1.674 & 303 & 24 & 303 & 1400 & 24 & - & 52 & 1200 & 1.9 & 3100 & 1.3 \\
\hline 11 & 1.116 & 303 & 24 & 303 & 160 & 24 & - & 56 & 3100 & 1.8 & 9500 & 1.3 \\
\hline 12 & 0.837 & 303 & 24 & 303 & 30 & 24 & - & 56 & 1050 & 1.8 & 2900 & 1.2 \\
\hline 13 & 0.833 & 318 & 2 & 318 & 15 & 24 & - & 70 & 1700 & 3.9 & 18500 & 2.1 \\
\hline 14 & 0.833 & 318 & 4 & 318 & 15 & 24 & - & 71 & 1400 & 3.9 & 15700 & 2.0 \\
\hline 15 & 0.833 & 318 & 6 & 318 & 15 & 24 & - & 69 & 2200 & 3.8 & 22800 & 2.2 \\
\hline 16 & 0.833 & 318 & 24 & 318 & 15 & 24 & - & 78 & 1100 & 4.9 & 15700 & 2.3 \\
\hline
\end{tabular}

* - large scale synthesis

$T_{1}$ - temperature of the acidic hydrolysis and oligomerization

$t_{1}$ - time of the acidic hydrolysis and oligomerization

$T_{2}$ - temperature of the basic condensation

$t_{2 \mathrm{a}}$ - time of formation of turbidity in the mixture

$t_{2 \mathrm{~b}}$ - time of basic condensation 


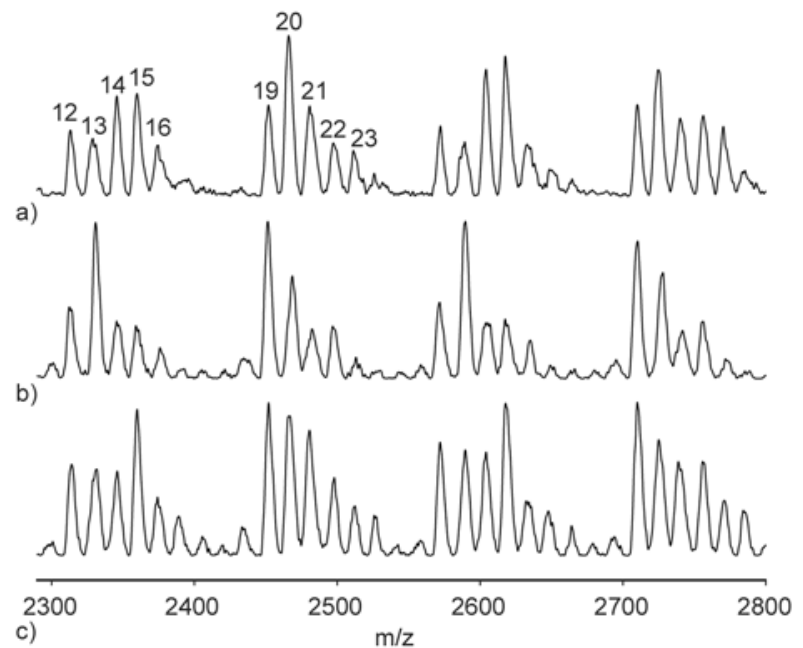

Figure 5. Microstructure (MALDI-TOF, DT, $\mathrm{Ag}^{+}$) of $\mathrm{Ph}-$ LPSQ prepared under different experimental conditions (a) 1d, (b) 6, (c) 2 (Table 1)

ences pointing to defects in the structure of sol-gel product (an additional, diffuse diffraction peak at about $0.77 \mathrm{~nm}$ and a decrease of the width of ladder segment $d_{1}$ owing to less regular arrangement of siloxane bonds in the polymer backbone). ${ }^{29} \mathrm{Si}$ NMR CPMAS traces (Figure 7) clearly show an incomplete condensation of Ph-LPSQ (a broad peak at $-70 \mathrm{ppm}$ corresponds to silanolated silsesquioxane groups $\mathrm{T}^{2}$, that were revealed by MALDI-TOF, along with all-siloxane condensed silsesquioxane units $\mathrm{T}^{3}$ at $-79 \mathrm{ppm}$ ). Vibrational spectra can be also very useful for the characterization of ladder silsesquioxanes.

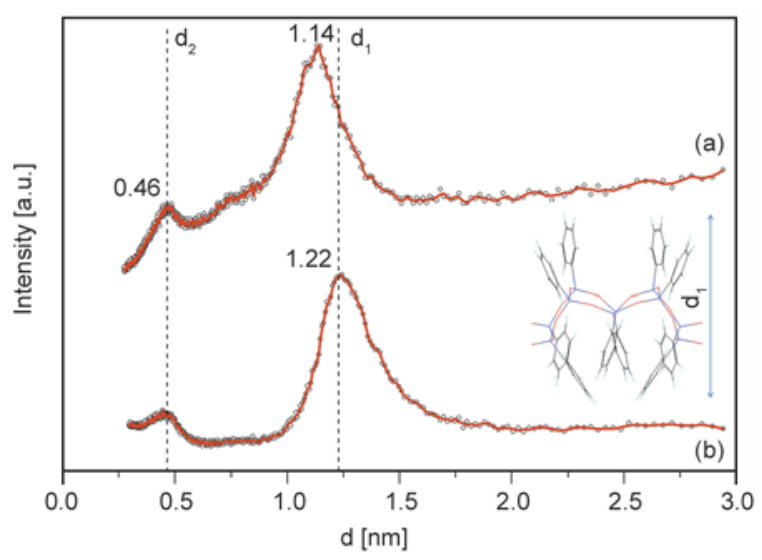

Figure 6. WAXS diffractograms of Ph-LPSQ (a) sample 1a and (b) model linear Ph-LPSQ

Theoretical studies [53] have proved that stretching vibrations of siloxane bonds in ladder LPSQ are represented by two peaks at about 1150 (ring-asym) and $1050 \mathrm{~cm}^{-1}$ (ring-sym). The more organized species, the more defined and separate $\mathrm{Si}-\mathrm{O}-\mathrm{Si}$ peaks should be. FTIR data (Figure 7) recorded for the obtained Ph-LPSQ are coherent with the theory. The structure of poly(phenylsilsesquioxanes) was found to be, typically for sol-gel reactions, dependent on the ratio $[\mathrm{SiOEt}] /\left[\mathrm{H}_{2} \mathrm{O}\right]$ and the reaction temperature. Thermal characteristics of the prepared Ph-LPSQ were obtained using DSC and TGA techniques. The polymers are amorphous and phase transitions that could possibly stem from their rigid structure were not recorded. Devitrification was not observed for

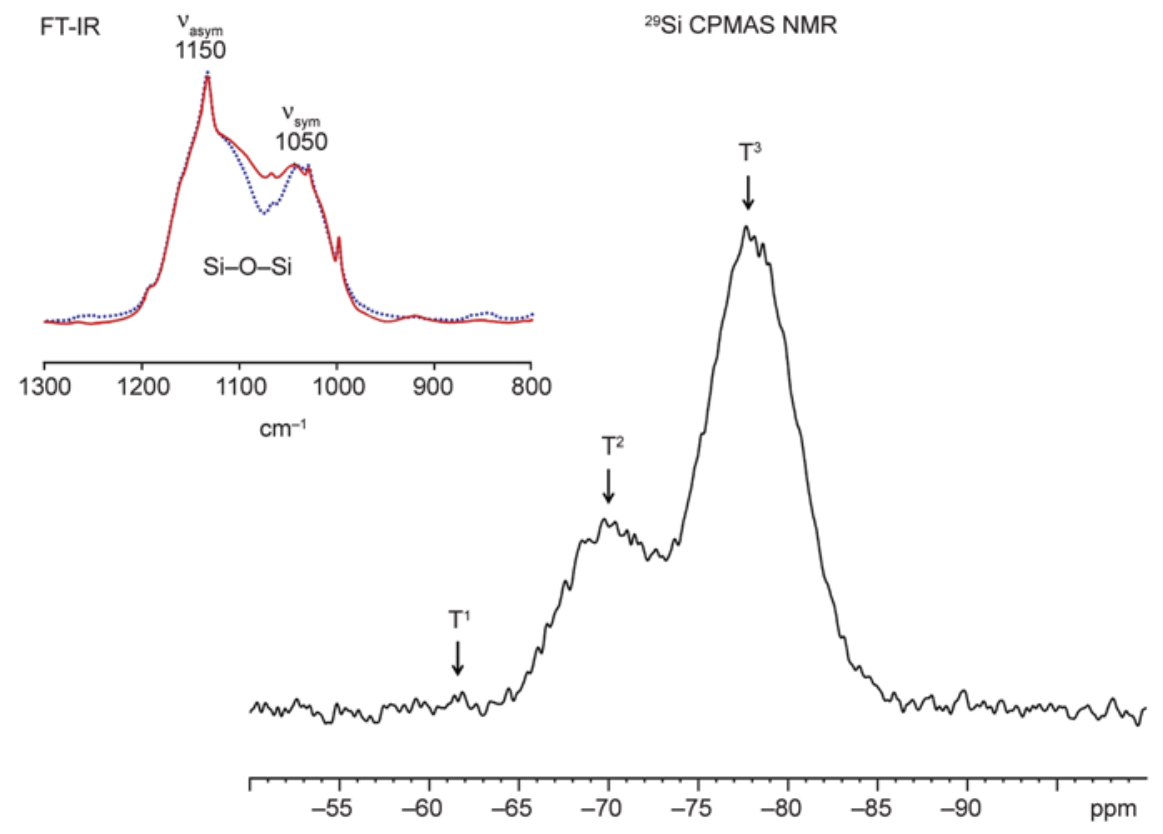

Figure 7. ${ }^{29} \mathrm{Si}$ CPMAS NMR of Ph-LPSQ (sample 5, Table 1) and FTIR spectra (insert) of Ph-LPSQ sample 1a (solid line) and model linear Ph-LPSQ (dot line) 
Ph-LPSQ of $\left.M_{\mathrm{w}}>5000\right)$. Double chain silsesquioxane backbone surrounded by phenyl groups is rigid (a certain amount of branching in Ph-LPSQ can additionally hinder the polymer mobility) and the $T_{\mathrm{g}}$ effect can be difficult to notice. However, less branched oligomers of low molecular mass $\left(M_{\mathrm{w}}<\right.$ 3000) exhibit a glass transition at $360 \mathrm{~K}$ (Figure 8). An endothermic change in a similar temperature range was observed for cross-linked poly(phenysilsesquioxane) particles obtained by a two-step acidbase catalysed sol-gel process $[21,22,54] . T_{\mathrm{g}}$ transition was not sensitive to the thermal treatment during DSC analysis. The reported value also did not change after an attempt to increase the cross-linking density by thermal condensation and azeotropic distillation of water with toluene.

The mechanism of thermal degradation of the obtained Ph-LPSQ was studied under an inert and oxidative atmosphere. The material was found to be thermally stable under both conditions (Figure 8). The main decomposition process in $\mathrm{N}_{2}$ takes place at $833 \mathrm{~K}$, irrespectively of the molecular mass. Minor transitions occur at $763 \mathrm{~K}$ (only for samples of low $\left.M_{\mathrm{w}}\right)$ and $953 \mathrm{~K}$. Residue left in $\mathrm{N}_{2}$ at $1173 \mathrm{~K}(71 \%)$ is larger than the calculated one (41\%), which suggests entrapment of carbon in the structure during the process [55]. TGA traces in $\mathrm{N}_{2}$ show also a small increase of sample weight above $1073 \mathrm{~K}$ that can be related to the formation of silicon nitride in the process of carbothermal reduction of $\mathrm{Si}-\mathrm{O}$ structures in the residue [56, 57]. Two step (833 and $923 \mathrm{~K}$ ) thermooxidative decomposition of Ph-LPSQ in air by release of benzene and combustion of the organic

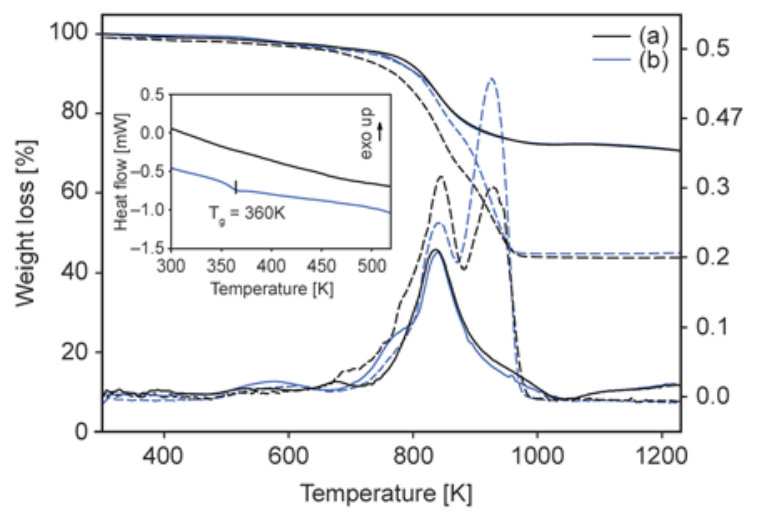

Figure 8. Thermal behavior of Ph-LPSQ of high and low $M_{\mathrm{w}}$ in $\mathrm{N}_{2}$ (solid lines) and in air (dashed lines) (TGA, $10 \mathrm{~K} / \mathrm{min}$ ) (a) $M_{\mathrm{w}}(\mathrm{MALLS}) 5000, M_{\mathrm{w}} / M_{\mathrm{n}}=$ 1.2 , (b) Mw(MALLS) 2500, $M_{\mathrm{w}} / M_{\mathrm{n}}=1.3$. The insert presents DSC traces $\left(10 \mathrm{~K} / \mathrm{min}, 2^{\text {nd }}\right.$ heating) of Ph-LPSQ of high and low $M_{\mathrm{w}}$. part results in the formation of silica (residue of $46 \%$, calculated 46.5\%). An analogous thermal behavior was reported for octahedral phenylsilsesquioxane, both in $\mathrm{N}_{2}$ and air [55].

\subsection{Dynamic light scattering studies of Ph-LPSQ micelles}

The size and structure of nanometric objects formed during precipitation of Ph-LPSQ [sample 1a, $\left.M_{\mathrm{w}}(\mathrm{MALLS})=2500, M_{\mathrm{w}} / M_{\mathrm{n}}=1.3\right]$ into a nonsolvent were studied using dynamic light scattering. Their time- and concentration-dependent behavior was monitored. The results demonstrate that Z-average diameter of nano-micelles and nano-spheres increases with the increasing concentration of oligomer solution and high concentration favours the formation of larger aggregates. The studies showed that in the case of a nonpolar nonsolvent (hexanes) the size of micelles reproducibly depends on the ratio between the polymer, solvent and nonsolvent (Figure 9). Micelles of about $200 \mathrm{~nm}$, that were formed at low concentrations of Ph-LPSQ $\left(a<4 \mathrm{mg} / \mathrm{cm}^{3}\right)$, tend to adsorb hexanes and swell slowly with time in a linear mode. At larger concentrations of $\mathrm{Ph}-$ LPSQ, the micelles tend to rapidly increase ( $a=$ $\left.5 \mathrm{mg} / \mathrm{cm}^{3}\right)$ and then precipitate $\left(a>5 \mathrm{mg} / \mathrm{cm}^{3}\right)$, which effectively decrease the amount of the polymer in suspension and leads to the formation of residual micelles of smaller size. An increase in the amount of hexanes caused formation of larger objects (Figure 10a) due to increased hydrostatic pressure. It augments the solvent flux through the wall of a micelle and destabilizes the system. Polar protic solvents $(\mathrm{EtOH})$ rapidly swell the micelles, especially

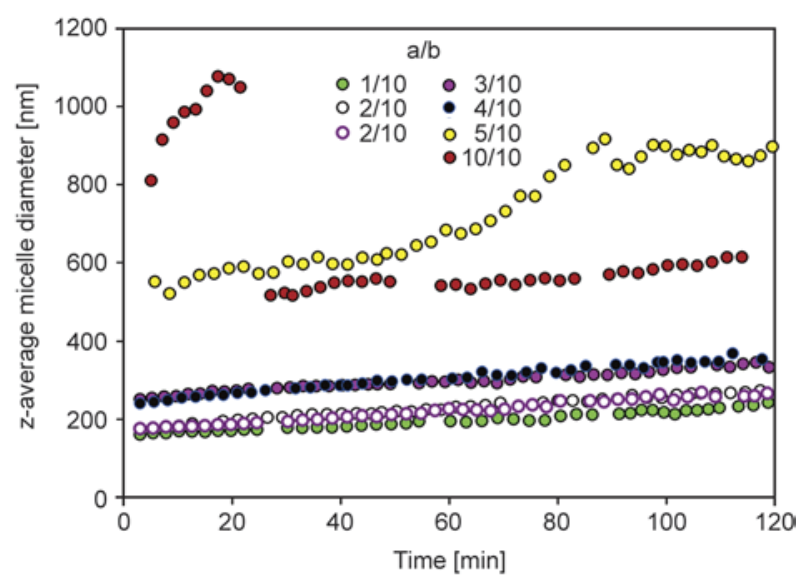

Figure 9. The behavior of Ph-LPSQ micelles in hexanes (aconcentration of Ph-LPSQ in $\mathrm{CH}_{2} \mathrm{Cl}_{2}\left[\mathrm{mg} / \mathrm{cm}^{3}\right]$, $\mathrm{b}$ - volume ratio: hexanes $/ \mathrm{CH}_{2} \mathrm{Cl}_{2}\left[\mathrm{~cm}^{3} / \mathrm{cm}^{3}\right]$ ) 

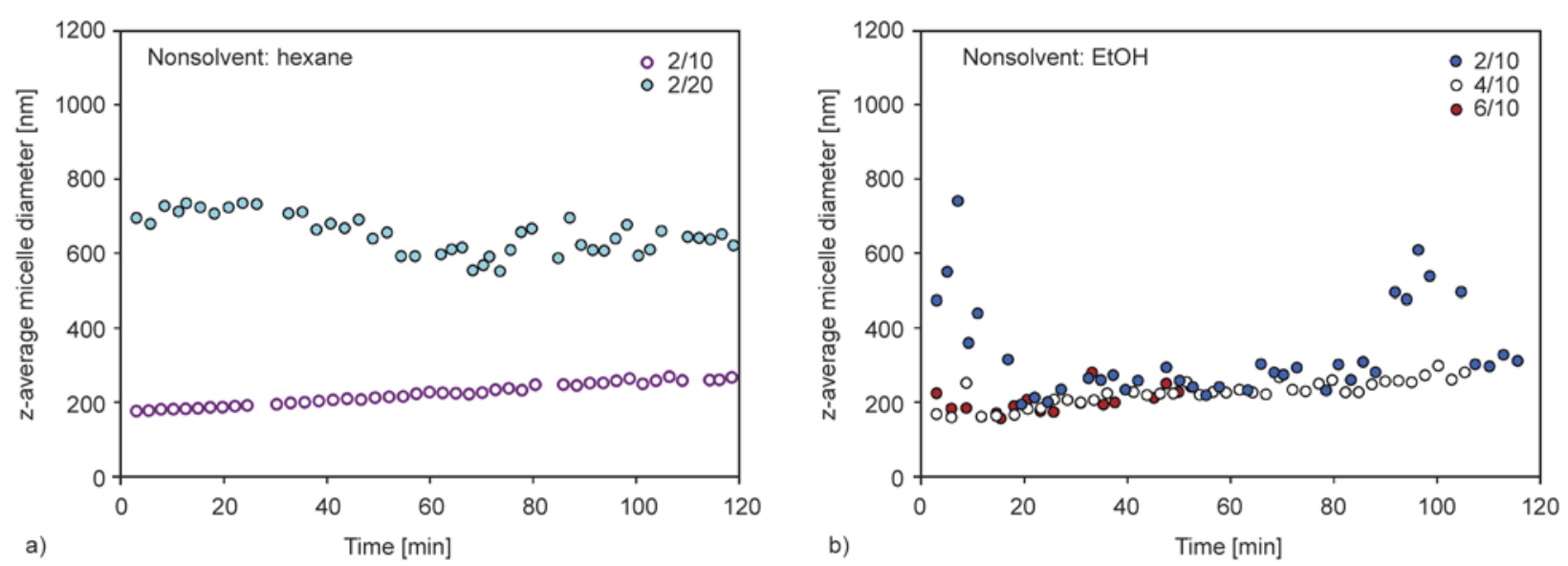

Figure 10. The effect of the amount of hexanes (a) and ethanol (b) on the change of size of micelles of Ph-LPSQ

at low polymer concentrations (Figure 10b). That low stability can be attributed to hydrogen bonding interactions between alcohol molecules and residual hydrophilic silanol moieties in the material.

The literature reports evidence similar phenomena, leading to the formation of spherical structures with a random-coil backbone conformation, for oligomers with large aromatic [58,59], dendritic [60] or amphiphilic [61, 62] side groups. Analogously, rigid rodflexible coil block copolymers can self-assemble in selective solvents into specific nanostructures with morphology governed by the geometric disparity between the rod and coil segments and anisotropic interactions between rod blocks (formation of liquid crystalline or crystalline structures) $[63,64]$. The process described herein is not typical, since microparticles are formed by rigid molecules with relatively small side substituents. The possible mechanism of micellization of Ph-LPSQ seems to resemble the one proposed for self-assembly of oligoacrylates bearing sterically hindered 1,10-bi-2-naphthalene side groups interacting through $\pi-\pi$ stacking $[58$, 59]. The micelle walls are made of densely packed molecular chains and the affinity among side groups helps in the formation of nanometer-scale spheres with minimum free energy. The structure of the forming micelles is stabilized by $\pi$ - $\pi$ inter- and intramolecular interactions between phenyl groups that belong to the neighboring silsesquioxane chains. Such $\pi-\pi$ conjugation in rigid segments can affect remarkably optical properties of the formed vesicles which can display e.g. switchable optical characteristics by external triggers [65].

\subsection{Fluorescence of $\mathbf{P h}-\mathrm{LPSQ}$}

Chromophoric side groups can offer a good way to study polymer dynamics and structure, providing there are appropriate and effective interactions between aromatic molecules [66, 67]. Hindered rotation about siloxane bonds in the double silsesquioxane chain of poly(phenylsilsesquioxanes) [48] prevents its folding and coil aggregation in solution that could result in fluorescence quenching. Fluorescence studies were thus carried out at room temperature for the prepared Ph-LPSQ (sample 1a, Table 1) both in solution and as micelles suspended in hexanes.

Emission spectra were recorded at $\lambda_{\text {ex }}=260 \mathrm{~nm}$ (Figure 11). Ph-LPSQ dissolved in dichloromethane

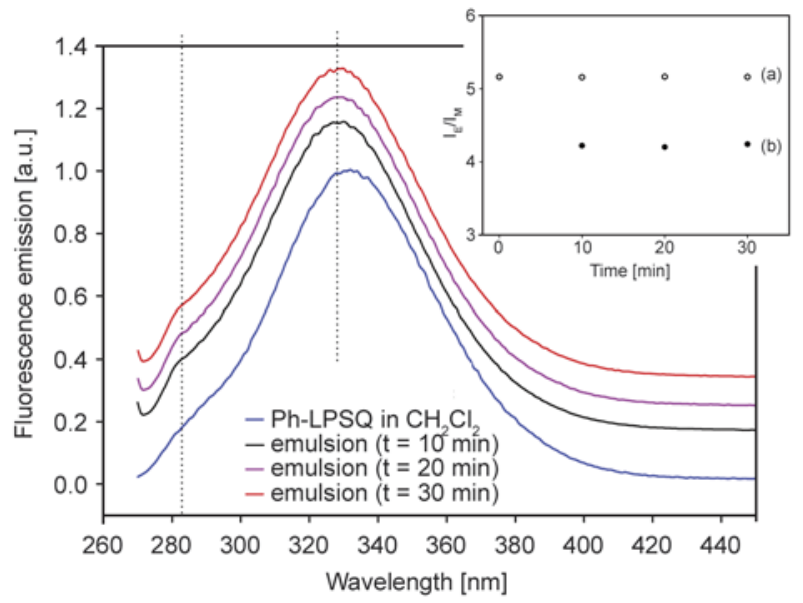

Figure 11. Emission fluorescence spectra $\left(\lambda_{\mathrm{ex}}=260 \mathrm{~nm}\right)$ and $I_{\mathrm{E}} / I_{\mathrm{M}}$ ratio plotted against the time of experiment (insert) for (a) Ph-LPSQ dissolved in dichloromethane (polymer concentration $a=$ $\left.0.18 \mathrm{mg} / \mathrm{cm}^{3}\right)$; or (b) suspended as micelles $(a=$ $0.18 \mathrm{mg} / \mathrm{cm}^{3}$; hexanes $/ \mathrm{CH}_{2} \mathrm{Cl}_{2} \mathrm{v} / \mathrm{v}=20 / 1$ ) 
show a weak emission peak of the single (monomeric) phenyl group (286 nm) and much stronger one for an excimer of sandwich geometry $(331 \mathrm{~nm})$. Samples of micellar structure exhibit a negligible blue shift ( $3 \mathrm{~nm}$ for both monomer and excimer), which can be caused by the change in solvent composition in the studied system. Fluorescence of micelles is stable over the experiment timescale. $I_{\mathrm{E}} / I_{\mathrm{M}}$ ratio for dissolved polymers is bigger than that for micelles (Figure 11, insert) which can be caused by fluorescence quenching due to the aggregation effect and increase of local concentration of phenyl groups in micelles.

Interesting effects were noted on increasing $\lambda_{\text {ex }}$ with energies close to the monomer emission $\left(\lambda_{\mathrm{ex}}=280\right.$ and $290 \mathrm{~nm}$ ) (Figure 12a). For the studied polymers the shape of emission bands at higher excitation wavelengths is different for microsuspension and the solution. In solution excitation at 280 and $290 \mathrm{~nm}$ give similar fluorescence profiles with quenched dimeric excimers $(331 \mathrm{~nm})$ and exposed small emission peaks. Possible ways leading to the emissions at wavelengths longer than that of an excimer nearest to the excitation wavelength include energy transfer and formation of excited multimers by interaction of an excited single phenyl with surrounding phenyl groups. Both paths require large density of phenyl aggregates of proper geometry to produce noticeable emissions. Polystyrene can be to some extent regarded as a model system for the studied PhLPSQ. It was found that formation of intramolecular excimers in polystyrenes of diverse structure and various sequence length of phenyl groups occurs primarily by interactions between vicinal chromo-

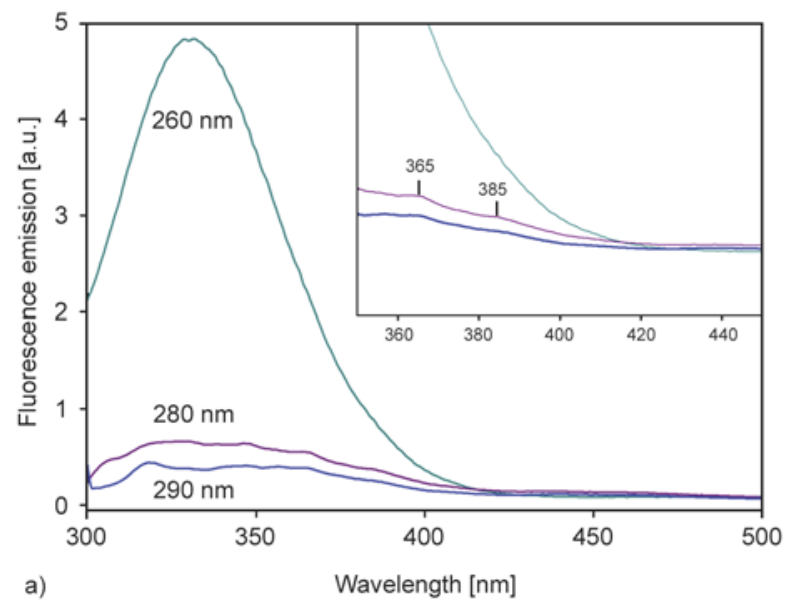

phores in the polymer chain [68] and depends upon the polymer molecular weight [69].

The analogous emission profile for Ph-LPSQ in suspension is different and changes with $\lambda_{\text {ex }}$ (Figure 12b). Fluorescence quenching at $\lambda_{\mathrm{ex}}=280 \mathrm{~nm}$ is less efficient than that in the solution. Intense Rayleigh scattering peaks can be observed, with maxima depending on the excitation wavelength, which points to the presence of defined particles in the studied mixture.

\subsection{Morphology of self-assembled structures}

Owing to the backbone rigidity and $\pi-\pi$ interactions between side substituents, oligomeric Ph-LPSQ can self-assemble spontaneously in template-free systems and form symmetrical, nonporous, nano- and microstructures $(\varphi<1 \mu \mathrm{m})$ in nonsolvents (polar protic alcohols and nonpolar nonprotic alkanes). Molecular mass is the restricting factor and only $\mathrm{Ph}$ LPSQ oligomers of $M_{\mathrm{w}}<3000$ formed suspensions on precipitation into a nonsolvent from their concentrated solutions in $\mathrm{CH}_{2} \mathrm{Cl}_{2}$. The stability of suspensions and the shape of particles that aggregated and precipitated under the studied conditions varied depending on the concentration ratio between $\mathrm{Ph}-$ LPSQ, solvent and non-solvent (Table 2). Spherical micelles are always formed in the initial stages of the process. It was proven by the structure of the sample presented on Figure 1, that was prepared in a small scale and under specific conditions (concentration of Ph-LPSQ in $\mathrm{CH}_{2} \mathrm{Cl}_{2}=50 \mathrm{mg} / \mathrm{cm}^{3}$, volume ratio hexanes $/ \mathrm{CH}_{2} \mathrm{Cl}_{2}=1000 \mathrm{~cm}^{3} / \mathrm{cm}^{3}$ ). Under more concentrated conditions the micelles tend to stick to each other and collapse into particles of irregular

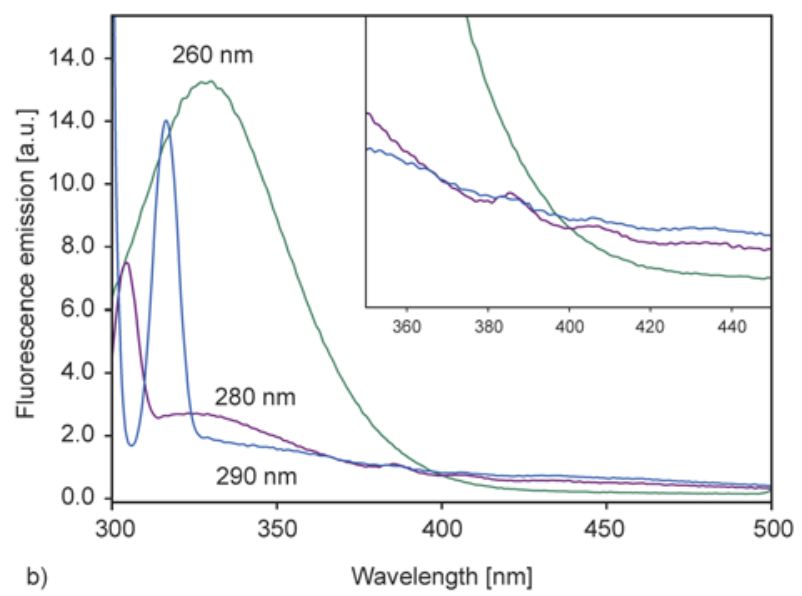

Figure 12. Fluorescence [not normalized spectra registered at $\lambda_{\mathrm{ex}}=260$ (green), 280 (violet) and $290 \mathrm{~nm}$ (blue)] of PhLPSQ (a) in solution in $\mathrm{CH}_{2} \mathrm{Cl}_{2}\left(a=0.18 \mathrm{mg} / \mathrm{cm}^{3}\right)$ and (b) as a micro-suspension $\left(a=0.18 \mathrm{mg} / \mathrm{cm}^{3}\right.$; hexanes $\left./ \mathrm{CH}_{2} \mathrm{Cl}_{2} \mathrm{v} / \mathrm{v}=20 / 1\right)$ 
Table 2. Conditions applied for the preparation of microstructured Ph-LPSQ in a template free system

\begin{tabular}{|l|c|c|c|c|c|c|c|c|c|c|}
\hline \multicolumn{1}{|c|}{ Sample } & 1-A & 1-B & 1-C & 1-D & 1-E & 1-F & 1-G & 1-H & 1-I & 1-J \\
\hline Polymer $[\mathrm{g}]$ & 1.0 & 1.0 & 1.0 & 1.0 & 1.0 & 0.10 & 0.10 & 0.05 & 0.025 & 1.0 \\
\hline$a\left[\mathrm{mg} / \mathrm{cm}^{3}\right]$ & 1000 & 200 & 50 & 500 & 330 & 100 & 100 & 50 & 25 & 50 \\
\hline$b\left[\mathrm{~cm}^{3} / \mathrm{cm}^{3}\right]$ & 100 & 100 & 100 & 50 & 33 & 50 & 50 & 50 & 50 & 100 \\
\hline Rotation $[\mathrm{rpm}]$ & 1000 & 1000 & 1000 & 1000 & 1000 & 1000 & 500 & 1000 & 1000 & 1000 \\
\hline
\end{tabular}

$a$ - concentration of Ph-LPSQ in $\mathrm{CH}_{2} \mathrm{Cl}_{2}$

$b$ - volume ratio: hexanes $/ \mathrm{CH}_{2} \mathrm{Cl}_{2}$

shape. The residual particles dispersed in non-solvent have spherical shapes.

The shape, size of microspheres and material distribution within the micelles were analyzed using scanning and transmission electron microscopy. TEM micrographs of precipitated Ph-LPSQ microspheres (not stained) show both isolated and aggregated units of spherical shape (diameters ranging from 50 $200 \mathrm{~nm}$ ) and dense internal packing. SEM images show that the obtained materials contain irregular but rather monodisperse particles. However, morphology of aggregated structures (Figure 13) varies depending on the oligomer precipitation conditions. The materials prepared with larger amounts of Ph-LPSQ (1-A and 1-D) have monolithic porous structure. Sample 1-D contains also a share of separated particles, which suggest formation of monoliths by aggregation and collapse of micelles. Other specimens display irregular particles, and their size differs with the quantity of polymer used (e.g. samples 1-F and 1-D). The rate of rotation in the system plays an important role for the particle shape. The lower the rate the more regular particles were formed (samples 1-F and 1-G).

\subsection{Porosity measurements}

A study was carried out to find a correlation between system parameters [polymer concentration (a) and the ratio of solvent and nonsolvent (b)] and the porous structure of the structured assemblies (Table 3). Specific surface area and pore size distributions of selected samples (1-A, 1-D, 1-E) were calculated using, respectively, the Brunauer-EmmettTeller (BET) and Barrett-Joyner-Halenda (BJH) methods (Table 3). Nitrogen sorption data show that all samples exhibit low surface area $\left(<7 \mathrm{~m}^{2} / \mathrm{g}\right)$ due to the presence of pores of average diameter in the range $7-13 \mathrm{~nm}$. However, their number is low and adsorption isotherms (Figure 14a) do not exhibit hysteresis loop typically associated with capillary condensation in mesoporous materials. Mercury intrusion was also used to characterize the obtained materials. The method is more suitable for macroporous samples and it can provide information about porosity in a wide pore range ( $<4 \mathrm{~nm}$ to $0.4 \mathrm{~mm}$ ). The estimated porosity (Table 3 ) is larger than $60 \%$ for all specimens but their total pore area is moderate (between 27 and $70 \mathrm{~m}^{2} / \mathrm{g}$; average pore diameter $85-600 \mathrm{~nm}$ ), depending on precipitation parameters. The comparison of the ratio of macropores/mesopores in the total porosity of the sample (Table 3 ) shows that the samples containing higher ratio of mesopores exhibit higher surface areas. However, if the general porosity of the sample is low (monolithic samples 1-A and 1-D) then their total surface area is low.

A significant difference concerning the average pore diameter can be observed between materials of irregular micellar structure and porous monoliths. A

Table 3. Nitrogen adsorption and $\mathrm{Hg}$ intrusion data summary

\begin{tabular}{|c|c|c|c|c|c|c|c|}
\hline \multirow{2}{*}{ Method } & Sample & 1-A & 1-D & 1-E & 1-B & $1-\mathrm{C}$ & 1-J \\
\hline & $\mathrm{a}\left[\mathrm{mg} / \mathrm{cm}^{3}\right]$ & 1000 & 500 & 330 & 200 & $\mathbf{5 0}$ & 50 \\
\hline \multirow{3}{*}{$\mathrm{N}_{2}$ adsorption } & BET surface area $\left[\mathrm{m}^{2} / \mathrm{g}\right]$ & 1.53 & 2.52 & 6.19 & - & - & - \\
\hline & BJH adsorption average pore diameter (4V/A) $[\mathrm{nm}]$ & 13.16 & 11.82 & 7.10 & - & - & - \\
\hline & BJH desorption average pore diameter (4V/A) [nm] & 8.99 & 7.79 & 6.64 & - & - & - \\
\hline \multirow{7}{*}{$\mathrm{Hg}$ intrusion } & total pore area $\left[\mathrm{m}^{2} / \mathrm{g}\right]$ & 69.95 & 60.39 & 27.36 & 27.09 & 64.40 & 162.74 \\
\hline & average pore diameter $(4 \mathrm{~V} / \mathrm{A})[\mu \mathrm{m}]$ & 0.085 & 0.155 & 0.595 & 0.557 & 0.266 & 0.103 \\
\hline & bulk density $\left[\mathrm{g} / \mathrm{cm}^{3}\right]$ & 0.43 & 0.29 & 0.19 & 0.20 & 0.20 & 0.21 \\
\hline & apparent (skeletal) density $\left[\mathrm{g} / \mathrm{cm}^{3}\right]$ & 1.16 & 0.90 & 0.84 & 0.78 & 1.20 & 1.39 \\
\hline & porosity $[\%]$ & 63.14 & 67.89 & 77.41 & 74.56 & 83.68 & 85.30 \\
\hline & macropores [\%] & 54.05 & 62.92 & 76.68 & 74.34 & 80.35 & 70.88 \\
\hline & mesopores [\%] & 9.09 & 4.97 & 0.73 & 0.22 & 3.33 & 14.42 \\
\hline
\end{tabular}

a - concentration of Ph-LPSQ in $\mathrm{CH}_{2} \mathrm{Cl}_{2}$ 

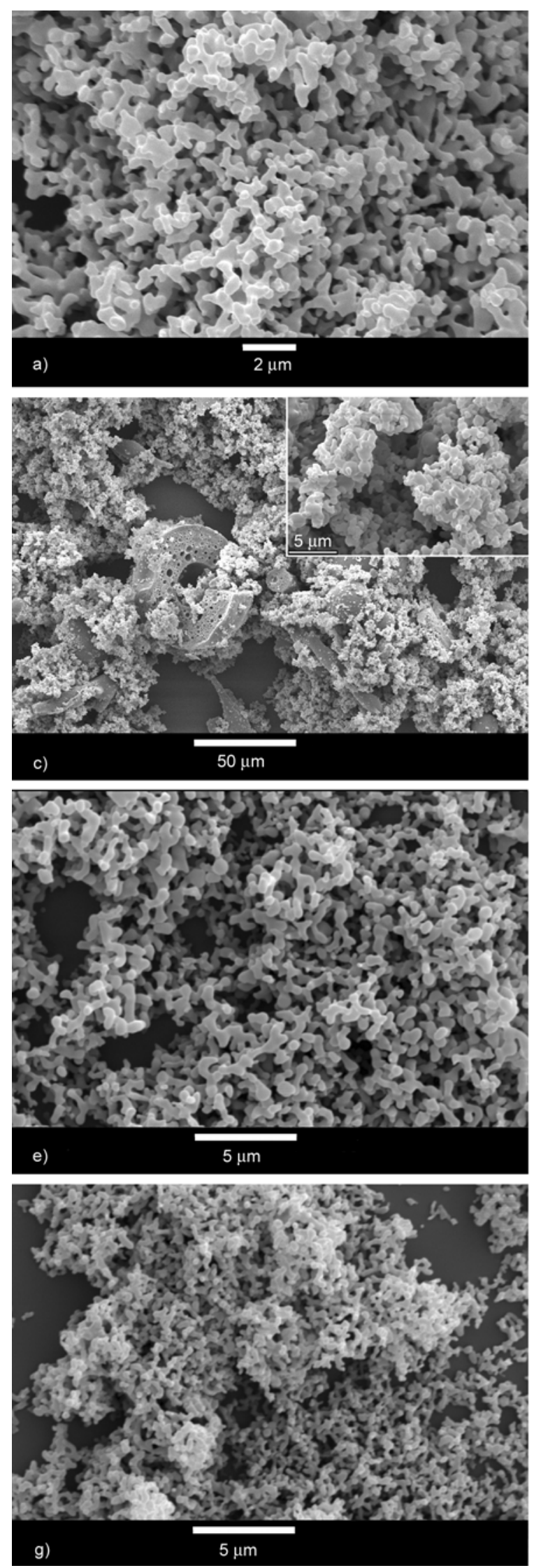
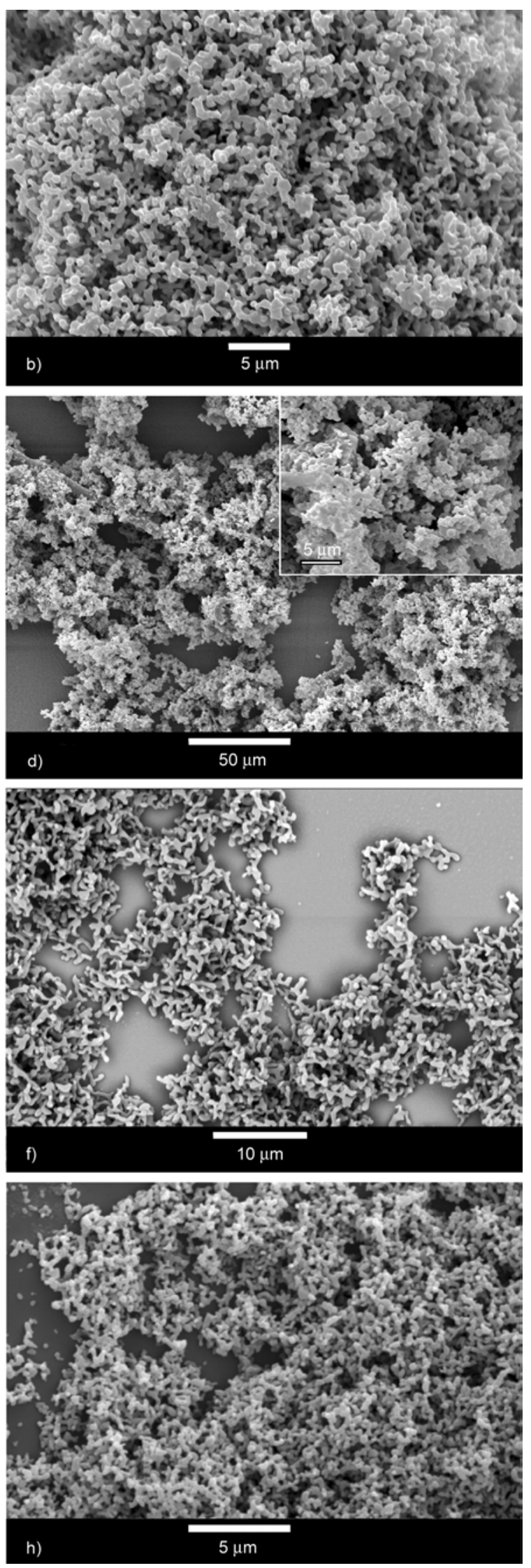

Figure 13. Scanning micrographs of samples a) 1-B, b) 1-C, c) 1-D, d) 1-E, e) 1-F, f) 1-G, g) 1-H, h) 1-I 
change of cumulative $\mathrm{Hg}$ intrusion volume in different ranges of pore diameters can be observed in the studied materials (Figure 14b). Two types of porosity, corresponding to SEM micrographs, can also be distinguished. All samples were evacuated to remove air and residual moisture from the pore system and mercury penetrates first all inter-particle voids and largest pores to reach a plateau intrusion at about $10 \mu \mathrm{m}$. Comparing to porous monoliths 1-A and 1-D, the increase of intrusion volume in samples 1-B, 1-C and 1-E suggests formation of large macropores as the micelles are linked on precipitation. Sample 1-D, that contains a larger share of micellar structures than 1-A, exhibits additional intrusion slope for pores of $\varphi$ about $1 \mu \mathrm{m}$. Both, 1-A and 1-D exhibit also a small increase of the volume of intruded $\mathrm{Hg}$ at about $20 \mathrm{~nm}$ that can be related to the size of pores detected by nitrogen adsorption. Cumulative pore area analysis (Figure 14b) shows that in samples 1-A and 1-D it is due only to small pores $(\varphi<50 \mathrm{~nm})$.

Species 1-B, 1-C and 1-E display multimodal pore size distribution. Apart from macrovoids patterned on linking of the precipitating micelles, pores of $\varphi$ about $1 \mu \mathrm{m}$ and smaller ( 15 and $25 \mathrm{~nm}$ ) are also formed during the process. Their size depends on the precipitation conditions. It suggests that such pores can be due to inter-granular voids formed by primary particles [70]. Sample 1-C, prepared with the lowest concentration of polymer solution and large volume of the nonpolar solvent have quite peculiar $\mathrm{Hg}$ intrusion characteristics. The presence of such a large amount of small pores $(\varphi<100 \mathrm{~nm})$ along with the macropores can be possibly related to the formation of empty vessels during the precipitation. Such objects can collapse more easily.

\subsection{Formation of porous silica-silsesquioxane hybrid materials using Ph-LPSQ}

Oligomeric Ph-LPSQ was also used for the modification of silica particles prepared in Stöber process. Materials of irregular structure (Figure 15) with particle surface covered with fine microfilaments were obtained using the precipitation procedure. Mercury intrusion data indicate that the material 1-J is porous (Figure 16), but its structure differs from the previously discussed macroporous samples. The pores are smaller (average $\varphi$ about 20-30 nm) but much more regular. The ratio mesopores/macropores, surface area and sample porosity are highest among the studies samples (Table 3 ) while the sample bulk density is comparable to that of macroporous materials (1-B, 1-C, 1-E).

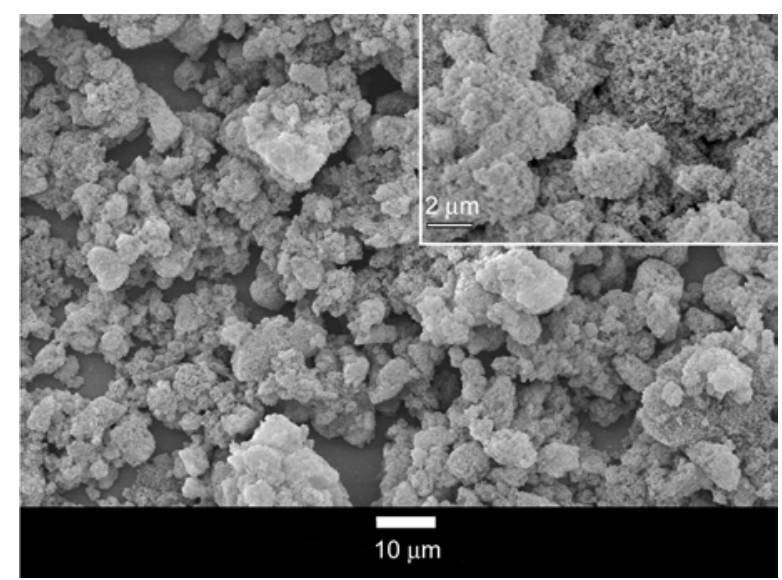

Figure 15. SEM micrograph Ph-LPSQ-SiO 2 hybrid (1-J)

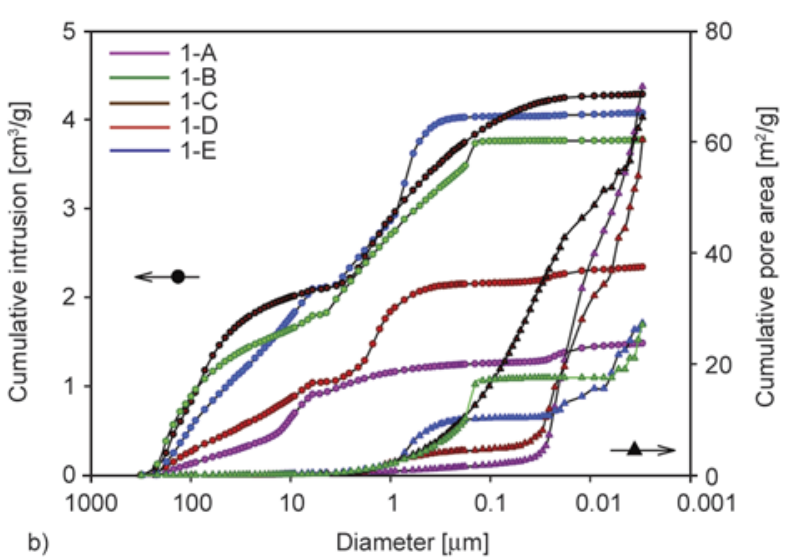

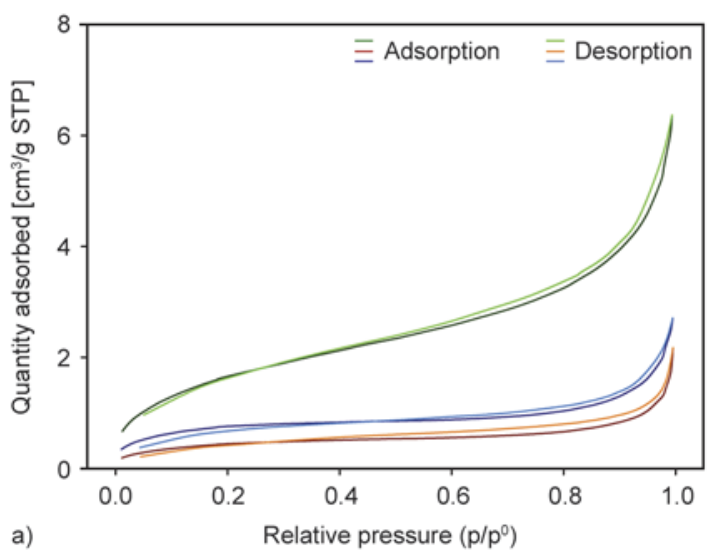

Figure 14. Porosity analysis of the structured Ph-LPSQ materials (a) $\mathrm{N}_{2}$ adsorption isotherms for samples 1-A (red), 1$\mathrm{D}$ (blue) and 1-E (green), (b) pore size distribution and cumulative pore area estimated by mercury intrusion porosimetry 


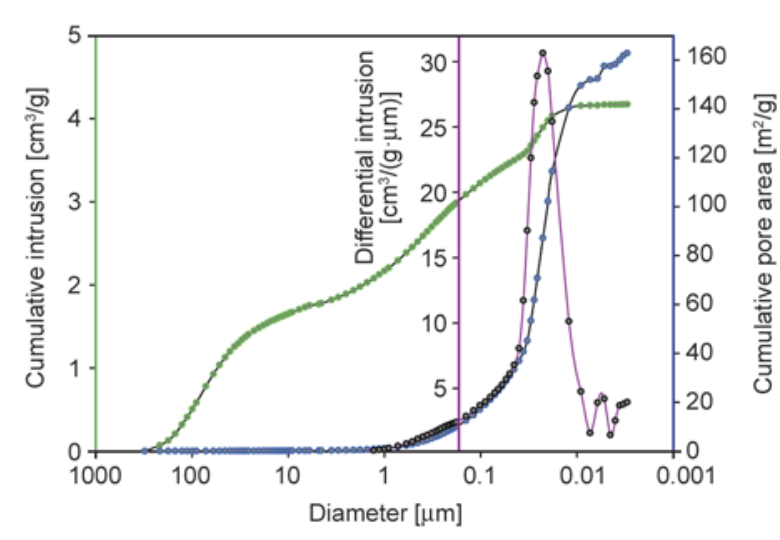

Figure 16. Porosity and surface parameters of Ph-LPSQ$\mathrm{SiO}_{2}$ hybrid (1-J)

\section{Conclusions}

Linear, oligomeric phenylsilsesquioxanes (Ph-LPSQ) can be obtained by a two-step, one-pot, acid/base sol-gel method carried out in bulk. MALDI-TOF analysis revealed that the oligomers are not defectfree, but the composition of the products can be adjusted with duration and temperature of the reaction stages. Oligomeric Ph-LPSQ and hybrid materials based on them are capable of formation of micro- and nanostructures due to morphology of silsesquioxane chain and spontaneous $\pi-\pi$ inter- and intramolecular associative interactions between side phenyl substituents. Micellar structures with minimum free energy are formed due to $\pi-\pi$ stacking of side phenyl groups in densely packed macromolecular chains. The size and shape of the formed particles and macropores is determined by the parameters of the process (concentration of Ph-LPSQ, solvent/nonsolvent ratio and rate of stirring).

The described method can be used for the preparation of polymeric microspheres in template-free systems. The formed macroporous materials can possibly have an applicative potential as chromatographic stationary phases or interesting precursors for silicon-oxycarbide glasses with high $\mathrm{C} / \mathrm{Si}$ ratio.

\section{Acknowledgements}

The authors thank Polish National Science Centre for the financial support within grant DEC-2011/03/B/ST5/02672 'Studies on preparation and structurization of new hybrid materials'. We are also grateful for analytic data provided by Mrs Beata Wiktorska (CMMS PAS - MALLS analysis) Mr. Marcin Florczak (CMMS PAS - MALDI-TOF), Mr. Przemysław Sowiński (CMMS PAS - TEM micrographs) and Dr. Marcin Kempiński (Kazimierz Wielki University in Bydgoszcz - mercury intrusion porosimetry measurements).

\section{References}

[1] Fu G-D., Li G. L., Neoh K. G., Kang E. T.: Hollow polymeric nanostructures - Synthesis, morphology and function. Progress in Polymer Science, 36, 127-167 (2011). DOI: 10.1016/j.progpolymsci.2010.07.011

[2] Wu S-H., Mou C-Y., Lin H. P.: Synthesis of mesoporous silica nanoparticles. Chemical Society Reviews, 42, 3862-3875 (2013). DOI: $10.1039 / \mathrm{c} 3 \operatorname{cs} 35405 \mathrm{a}$

[3] Giraldo L. F., López B. L., Pérez L., Urrego S., Sierra L., Mesa M.: Mesoporous silica applications. Macromolecular Symposia, 258, 129-141 (2007). DOI: $10.1002 /$ masy.200751215

[4] Argyo C., Weiss W., Bräuchle C., Bein T.: Multifunctional mesoporous silica nanoparticles as a universal platform for drug delivery. Chemistry of Materials, 26, 435-451 (2014).

DOI: $10.1021 / \mathrm{cm} 402592 \mathrm{t}$

[5] Tang F., Li L., Chen D.: Mesoporous silica nanoparticles: Synthesis, biocompatibility and drug delivery. Advanced Materials, 24, 1504-1534 (2012). DOI: $10.1002 / \mathrm{adma} .201104763$

[6] Colilla M., González B., Vallet-Regí M.: Mesoporous silica nanoparticles for the design of smart delivery nanodevices. Biomaterials Science, 1, 114-134 (2013). DOI: $10.1039 / \mathrm{c} 2 \mathrm{bm} 00085 \mathrm{~g}$

[7] Guo X., Yu H., Yang H., Kanamori K., Zhu Y., Nakanishi K.: Pore structure control of macroporous methylsilsesquioxane monoliths prepared by in situ two-step processing. Journal of Porous Materials, 20, 14771483 (2013).

DOI: $10.1007 / \mathrm{s} 10934-013-9733-\mathrm{Z}$

[8] Nakanishi K., Shikata H., Ishizuka N., Koheiya N., Soga N.: Tailoring mesopores in monolithic macroporous silica for HPLC. Journal of High Resolution Chromatography, 23, 106-110 (2000).

DOI: $10.1002 /($ SICI) 1521-4168(20000101)23:1<106:

\section{AID-JHRC106>3.0.CO;2-1}

[9] Cademartiri R., Brook M. A., Pelton R., Brennan J. D.: Macroporous silica using a 'sticky' Stöber process. Journal of Materials Chemistry, 19, 1583-1592 (2009). DOI: $10.1039 / \mathrm{b} 815447 \mathrm{c}$

[10] Rajendra V., Brook M. A.: Controlled formation of macroporous or hollow silica particles in non-aqueous silicone dispersions. RSC Advances, 3, 22229-22238 (2013).

DOI: $10.1039 / \mathrm{c} 3 \mathrm{ra} 45182 \mathrm{~h}$

[11] Nakanishi K., Amatani T., Yano S., Kodaira T.: Multiscale templating of siloxane gels via polymerizationinduced phase separation. Chemistry of Materials, 20, 1108-1115 (2008).

DOI: $10.1021 / \mathrm{cm} 702486 \mathrm{~b}$

[12] Nakanishi K., Kanamori K.: Organic-inorganic hybrid poly(silsesquioxane) monoliths with controlled macroand mesopores. Journal of Materials Chemistry, 15, 3776-3786 (2005). DOI: $10.1039 / \mathrm{b} 508415 \mathrm{f}$ 
[13] Dong H., Brennan J. D.: Macroporous monolithic methylsilsesquioxanes prepared by a two-step acid/acid processing method. Chemistry of Materials, 18, 41764182 (2006).

DOI: $10.1021 / \mathrm{cm} 060509 \mathrm{e}$

[14] Dong H., Brennan J. D.: Controlling the morphology of methylsilsesquioxane monoliths using a two-step processing method. Chemistry of Materials, 18, 541-546 (2006).

DOI: $10.1021 / \mathrm{cm} 051900 \mathrm{n}$

[15] Stein A., Li F., Denny N. R.: Morphological control in colloidal crystal templating of inverse opals, hierarchical structures, and shaped particles. Chemistry of Materials, 20, 649-666 (2008).

DOI: $10.1021 / \mathrm{cm} 702107 \mathrm{n}$

[16] Loiola A. R., da Silva L., Cubillas P., Anderson M. W.: Synthesis and characterization of hierarchical porous materials incorporating a cubic mesoporous phase. Journal of Materials Chemistry, 18, 4985-4993 (2008). DOI: $10.1039 / \mathrm{B} 806674 \mathrm{D}$

[17] Wang Z. Y., Stein A.: Morphology control of carbon, silica, and carbon/silica nanocomposites: From 3D ordered macro-/mesoporous monoliths to shaped mesoporous particles. Chemistry of Materials, 20, 10291040 (2008).

DOI: $10.1021 / \mathrm{cm} 0717864$

[18] Arkhireeva A., Hay J. N.: Synthesis of sub-200 nm silsesquioxane particles using a modified Stöber solgel route. Journal of Materials Chemistry, 13, 31223127 (2003).

DOI: $10.1039 / \mathrm{b} 306994 \mathrm{j}$

[19] Jiang K., Chi F., Li B., Jiang B.: A facile method for preparation of hollow polyphenylsilsesquioxane microspheres. Chemistry Letters, 37, 492-493 (2008). DOI: $10.1246 / \mathrm{cl} .2008 .492$

[20] Ma C., Kimura Y.: Preparation of nano-particles of poly(phenylsilsesquioxane)s by emulsion polycondensation of phenylsilanetriol formed in aqueous solution. Polymer Journal, 34, 709-713 (2002).

DOI: $10.1295 /$ polymj.34.709

[21] Takahashi K., Tadanaga K., Hayashi A., Matsuda A., Tatsumisago M.: Glass transition and thermal softening of poly(phenylsilsesquioxane) particles prepared using two-step acid-base catalyzed sol-gel process. Journal of Non-Crystalline Solids, 354, 700-704 (2008). DOI: 10.1016/j.jnoncrysol.2007.07.073

[22] Takahashi K., Tadanaga K., Hayashi A., Matsuda A., Katagiri K., Tatsumisago M.: Structure of polyphenylsilsesquioxane particles prepared by two-step acidbase catalyzed sol-gel process and formation of hollow particles. Journal of Nanoscience and Nanotechnology, 7, 3307-3312 (2007).

DOI: $10.1166 /$ jnn.2007.659
[23] Matsuda A., Sasaki T., Hasegawa K., Tatsumisago M., Mianmi T.: Thermal softening behavior of poly(phenylsilsesquioxane) and poly(benzylsilsesquioxane) particles. Journal of the Ceramic Society of Japan, 108, 830-835 (2000). DOI: $10.2109 /$ jcersj.108.1261 830

[24] Takahashi K., Tadanaga K., Matsuda A., Hayashi A., Tatsumisago M.: Thermoplastic and thermosetting properties of polyphenylsilsesquioxane particles prepared by two-step acid-base catalyzed sol-gel process. Journal of Sol-Gel Science and Technology, 41, 217222 (2007).

DOI: $10.1007 / \mathrm{s} 10971-006-1501-\mathrm{y}$

[25] Lee A. S. S., Choi S-S., Jang S-H., Hwang S. S., Baek K-Y.: Preparation of high modulus thin films based on photocurable azido-functionalized ladder-like structured polysilsesquioxanes. Macromolecular Research, 22, 1109-1114 (2014).

DOI: $10.1007 / \mathrm{s} 13233-014-2152-4$

[26] Kaneko Y., Toyodome H., Mizumo T., Shikinaka K., Iyi N.: Preparation of a sulfo-group-containing rodlike polysilsesquioxane with a hexagonally stacked structure and its proton conductivity. Chemistry - A European Journal, 20, 9394-9399 (2014).

DOI: $10.1002 /$ chem.201402011

[27] Lee S-H., Lim J-H., Kim K-M.: Fabrication of hybrid ladderlike polysilsesquioxane-grafted multiwalled carbon nanotubes. Journal of Applied Polymer Science, 124, 3792-3798 (2012).

DOI: $10.1002 / a p p .35389$

[28] Baney R. H., Itoh Maki I., Sakakibara A., Suzuki T.: Silsesquioxanes. Chemical Reviews, 95, 1409-1430 (1995). DOI: $10.1021 / \mathrm{cr} 00037 \mathrm{a} 012$

[29] Brown J. F.: Double chain polymers and nonrandom crosslinking. Journal of Polymer Science Part C: Polymer Symposia, 1, 83-97 (1963).

DOI: $10.1002 /$ polc. 5070010106

[30] Ainuddin A. R., Hakiri N., Muto H., Sakai M., Matsuda A.: Mechanical properties comparison of phenylsilsesquioxane-methylsilsesquioxane hybrid films by indentation. Journal of the Ceramic Society of Japan, 119, 490-493 (2011).

DOI: $10.2109 /$ jcersj2.119.490

[31] Li G. Z., Matsuda T., Nishioka A., Miyata K., Masubuchi Y., Koyama K., Pittman C. U. Jr.: Rheological properties of polystyrene blends with rigid ladderlike polyphenylsilsesquioxane. Journal of Applied Polymer Science, 96, 706-713 (2005).

DOI: 10.1002/app.21503

[32] Prado L. A. S. A., Sforça M. L., de Oliveira A. G., Yoshida I. V. P.: Poly(dimethylsiloxane) networks modified with poly(phenylsilsesquioxane)s: Synthesis, structural characterisation and evaluation of the thermal stability and gas permeability. European Polymer Journal, 44, 3080-3086 (2008).

DOI: 10.1016/j.eurpolymj.2008.07.002 
[33] Lee A. S., Baek K-Y., Hwang S. S.: Synthesis of a photocurable ladder-like poly(phenyl-co-mercaptopropyl) silsesquioxane as gate dielectric material. Molecular Crystals and Liquid Crystals, 580, 88-94 (2013). DOI: 10.1080/15421406.2013.807720

[34] Hong-Ji C., Meng F.: Core-shell-shaped organic-inorganic hybrid as pore generator for imprinting nanopores in organosilicate dielectric films. Macromolecules, 40, 2079-2085 (2007).

DOI: $10.1021 / \mathrm{ma} 062471 \mathrm{x}$

[35] Chen W-C., Liu W-C., Wu P-T., Chen P-F.: Synthesis and characterization of oligomeric phenylsilsesquioxane-titania hybrid optical thin films. Materials Chemistry and Physics, 83, 71-77 (2004).

DOI: 10.1016/j.matchemphys.2003.09.039

[36] Yang H., Cheng Y., Xiao F.: Thermal stable superhydrophobic polyphenylsilsesquioxane/nanosilica composite coatings. Applied Surface Science, 258, 15721580 (2011).

DOI: 10.1016/j.apsusc.2011.09.137

[37] Meier A., Weinberger M., Pinkert K., Oschatz M., Paasch S., Giebeler L., Althues H., Brunner E., Eckert J., Kaskel S.: Silicon oxycarbide-derived carbons from a polyphenylsilsequioxane precursor for supercapacitor applications. Microporous and Mesoporous Materials, 188, 140-148 (2014).

DOI: $10.1016 /$ j.micromeso.2013.12.022

[38] Kang D. W., Kim S. T., Kim Y. M.: Preparation and characteristics of polyphenylsilsesquioxane- $b$-polyurethane copolymer as a dielectric material. Journal of Inorganic and Organometallic Polymers, 13, 157-170 (2003). DOI: 10.1023/A:1025836316494

[39] Lee A. S., Choi S-S., Lee H. S., Jeon H. Y., Baek K-Y., Hwang S. S.: Synthesis and characterization of organicinorganic hybrid block copolymers containing a fully condensed ladder-like polyphenylsilsesquioxane. Journal of Polymer Science Part A: Polymer Chemistry, 50, 4563-4570 (2012).

DOI: $10.1002 /$ pola.26269

[40] Jiang Y., Li X., Yang R.: Polycarbonate composites flame-retarded by polyphenylsilsesquioxane of ladder structure. Journal of Applied Polymer Science, 124, 4381-4388 (2012).

DOI: $10.1002 / a p p .35428$

[41] Ren Z., Zhang R., Wang F., Yan S.: A study on the hydrogen bonding interaction of the electrospun ladder polyphenylsilsesquioxane/polyisophthalamide composite fibers by ATR FT-IR. Polymer Chemistry, 2, 608 613 (2011). DOI: $10.1039 / \mathrm{c} 0$ py00274g

[42] de Omena Pina S. R., Pardini L. C., Yoshida I. V. P.: Carbon fiber/ceramic matrix composites: Processing, oxidation and mechanical properties. Journal of Materials Science, 42, 4245-4253 (2007).

DOI: $10.1007 / \mathrm{s} 10853-006-0688-1$
[43] Kummari S. V. K. R., Kummara M. R., Palem R. R., Nagellea S. R., Shchipunov Y., Ha C-S.: Chitosanpoly(aminopropyl/phenylsilsesquioxane) hybrid nanocomposite membranes for antibacterial and drug delivery applications. Polymer International, 64, 293-302 (2015).

DOI: $10.1002 /$ pi.4789

[44] Li P-F., Yan S-K., Ren Z-J.: An optical microscopy study on the solvent-induced crystalline morphology of ladder polyphenylsilsesquioxane. Acta PhysicoChimica Sinica, 28, 494-498 (2012).

DOI: $10.3866 /$ PKU.WHXB201111233

[45] Li G. Z., Yamamoto T., Nozaki K., Hikosaka M.: Studies on morphology of single crystals of ladder-like polyphenylsilsesquioxane (PPSQ) by polarized optical microscopy. Macromolecular Chemistry and Physics, 201, 1283-1285 (2000).

DOI: 10.1002/1521-3935(20000801)201:12<1283:: AID-MACP1283>3.0.CO;2-1

[46] Li G., Yamamoto T., Nozaki K., Hikosaka M.: Crystallization of ladderlike polyphenylsilsesquioxane (PPSQ)/ isotactic polystyrene (i-PS) blends. Polymer, 42, 84358441 (2001).

DOI: 10.1016/S0032-3861(01)00326-3

[47] Kim K-M., Ogoshi T., Chujo Y.: Controlled polymer hybrids with ladderlike polyphenylsilsesquioxane as a template via the sol-gel reaction of phenyltrimethoxysilane. Journal of Polymer Science Part A: Polymer Chemistry, 43, 473-478 (2005).

DOI: $10.1002 /$ pola.20571

[48] Liu C., Liu Y., Shen Z., Xie P., Zhang R., Yang J., Bai F.: Study of the steric tacticity of novel soluble ladderlike poly(phenylsilsesquioxane) prepared by stepwise coupling polymerization. Macromolecular Chemistry and Physics, 202, 1581-1585 (2001).

DOI: 10.1002/1521-3935(20010601)202:9<1581::AIDMACP1581>3.0.CO;2-5

[49] Armarego W. L. F., Chai Ch. L. L.: Purification of laboratory chemicals. Elsevier Science (2003).

[50] Brinker C. J.: Hydrolysis and condensation of silicates: Effects on structure. Journal of Non-Crystalline Solids, 100, 31-50 (1988).

DOI: 10.1016/0022-3093(88)90005-1

[51] Kim H-J., Lee J-K., Park S-J., Ro H. W., Yoo D. Y., Yoon D. Y.: Observation of low molecular weight poly(methylsilsesquioxane)s by graphite plate laser desorption/ionization time-of-flight mass spectrometry. Analytical Chemistry, 72, 5673-5678 (2000).

DOI: 10.1021/ac0003899

[52] Ro H. W., Park E. S., Soles C. L., Yoon D. Y.: Structure-property relationships for methylsilsesquioxanes. Chemistry of Materials, 22, 1330-1339 (2010). DOI: $10.1021 / \mathrm{cm} 901771 \mathrm{y}$

[53] Park E. S., Ro H. W., Nguyen C. V., Jaffe R. L., Yoon D. Y.: Infrared spectroscopy study of microstructures of poly(silsesquioxane)s. Chemistry of Materials, 20, 1548-1554 (2008).

DOI: $\underline{10.1021 / \mathrm{cm} 071575 \mathrm{z}}$ 
[54] Takahashi K., Tadanaga K., Matsuda A., Hayashi A., Tatsumisago M.: Effects of phenyltriethoxysilane concentration in starting solutions on thermal properties of polyphenylsilsesquioxane particles prepared by a twostep acid-base catalyzed sol-gel process. Journal of the Ceramic Society of Japan, 115, 131-135 (2007).

DOI: $10.2109 /$ jcersj.115.131

[55] Fina A., Tabuani D., Carniato F., Frache A., Boccaleri E., Camino G.: Polyhedral oligomeric silsesquioxanes (POSS) thermal degradation. Thermochimica Acta, 440, 36-42 (2006).

DOI: $10.1016 /$ j.tca.2005.10.006

[56] Shi Y., Wan Y., Zhao D.: Ordered mesoporous nonoxide materials. Chemical Society Reviews, 40, 38543878 (2011).

DOI: $10.1039 / \mathrm{c} 0 \mathrm{cs} 00186 \mathrm{~d}$

[57] Kapoor M. P., Inagaki S.: Synthesis of mesoporous silicon oxynitrides via direct nitridation with nitrogen. Chemistry Letters, 32, 94-95 (2003).

DOI: $10.1246 / \mathrm{cl} .2003 .94$

[58] Liu N., Wang X., Cao H., Chen C., Zhang W., Wei Y.: Concentration-dependent self-assembly of a novel comb oligomer having rigid binaphthyl macrocyclic pendants. Macromolecular Rapid Communications, 26, 1925-1930 (2005).

DOI: $10.1002 /$ marc. 200500570

[59] Liu N., Wang X., Jin E., Chen C., Zhang W., Wei Y.: Synthesis and self-assembly of comb oligomers having rigid racemic or chiral binaphthyl macrocyclic pendant groups. Polymer, 47, 3021-3027 (2006).

DOI: 10.1016/j.polymer.2006.03.018

[60] Percec V., Ahn C-H., Ungar G., Yeardley D. J. P., Möller M., Sheiko S. S.: Controlling polymer shape through the self-assembly of dendritic side-groups. Nature, 391, 161-164 (1998).

DOI: $10.1038 / 34384$

[61] Basu S., Vutukuri D. R., Shyamroy S., Sandanaraj B. S., Thayumanavan S.: Invertible amphiphilic homopolymers. Journal of the American Chemical Society, 126, 9890-9891 (2004).

DOI: $10.1021 / \mathrm{ja} 047816 \mathrm{a}$

[62] El Kadib N. A., Finiels A., Marcotte N., Brunel D.: Self-templating amphiphilic polysiloxanes to design nanostructured silica-based architectures. Chemical Communications, 49, 5168-5170 (2013).

DOI: $10.1039 / \mathrm{c} 3 \mathrm{cc} 41943 \mathrm{f}$
[63] Chen L., Shen H., Eisenberg A.: Kinetics and mechanism of the rod-to-vesicle transition of block copolymer aggregates in dilute solution. Journal of Physical Chemistry B, 103, 9488-9497 (1999).

DOI: $10.1021 /$ jp9913665

[64] Zhang J., Chen X-F., Wei H-B., Wan X-H.: Tunable assembly of amphiphilic rod-coil block copolymers in solution. Chemical Society Reviews, 42, 9127-9154 (2013).

DOI: $10.1039 / \mathrm{c} 3 \operatorname{cs} 60192 \mathrm{~g}$

[65] Liu C-L., Lin C-H., Kuo C-C., Lin S-T., Chen W-C.: Conjugated rod-coil block copolymers: Synthesis, morphology, photophysical properties, and stimuliresponsive applications. Progress in Polymer Science, 36, 603-637 (2011). DOI: $10.1016 /$ j.progpolymsci.2010.07.008

[66] Hunter C. A., Sanders J. K. M.: The nature of $\pi-\pi$ interactions. Journal of the American Chemical Society, 112, 5525-5534 (1990).

DOI: $10.1021 / \mathrm{ja} 00170 \mathrm{a} 016$

[67] Snyder S. E., Huang B-S., Chu Y. W., Lin H-S., Carey J. R.: The effects of substituents on the geometry of $\pi-\pi$ interactions. Chemistry - A European Journal, 18, 12663-12671 (2012).

DOI: $10.1002 /$ chem.201202253

[68] Lindsell W. E., Robertson F. C., Soutar I.: Intramolecular excimer formation in macromolecules - V. Headto-head polystyrene, block copolymers of styrene and butadiene and regular condensation polymers of $\alpha$ methylstyrene. European Polymer Journal, 17, 203208 (1981).

DOI: 10.1016/0014-3057(81)90154-3

[69] Abuin E., Lissi E., Gargallo L., Radic D.: Polystyrene fluorescence spectra. Molecular weight dependence in different solvents. European Polymer Journal, 20, 105107 (1984).

DOI: $10.1016 / 0014-3057(84) 90233-7$

[70] Giesche H.: Mercury porosimetry: A general (practical) overview. Particle and Particle Systems Characterization, 23, 9-19 (2006). DOI: $10.1002 /$ ppsc. 200601009 